\title{
A Case Study of Vacuum Tube-Well Dewatering Technology for Improving Deep Soft Soil in Yangtze River Floodplain
}

\section{Biao Zeng}

Southeast University School of Transportation

\section{Yu Zhen}

Nanjing Darcy Geotechnical Engineering Co., Ltd.

Dingwen Zhang ( $\sim$ zhangdw@seu.edu.cn )

Southeast University https://orcid.org/0000-0003-1602-5205

\section{Tao Meng}

China Tiesiju Civil Engineering Group Co., Ltd.

\section{Zejia Gong}

Southeast University School of Transportation

\section{Songyu Liu}

Southeast University School of Transportation

\section{Research Article}

Keywords: vacuum tube-well, pumping test ground settlement, water drawdown level, CPTU, Yangtze River Floodplain

Posted Date: June 21st, 2021

DOl: https://doi.org/10.21203/rs.3.rs-174384/v1

License: (c) (i) This work is licensed under a Creative Commons Attribution 4.0 International License. Read Full License 


\section{Title Page:}

\section{A Case Study of Vacuum Tube-well Dewatering Technology for Improving Deep Soft Soil in Yangtze River Floodplain}

Biao Zeng ${ }^{1,2}$, Yu Zhen ${ }^{3}$, Dingwen Zhang ${ }^{1,2 *}$, Tao Meng ${ }^{4}$, Zejia Gong ${ }^{1}$, Songyu Liu ${ }^{1}$

1 School of Transportation, Southeast University, Nanjing, Jiangsu Province 211189, China;

2 National Demonstration Center for Experimental Road and Traffic Engineering Education (Southeast University), Nanjing, Jiangsu Province, 211189,China ;

3 Nanjing Darcy Geotechnical Engineering Co., Ltd., Nanjing; Jiangsu Province 210041, China;

4 China Tiesiju Civil Engineering Group Co., Ltd., Hefei; Anhui Province 230022, China;

*Correspondence: Dingwen Zhang;

School of Transportation, Southeast University, Nanjing, Jiangsu 211189, China;

Email: zhangdw@seu.edu.cn ;

ORCID ID: https://orcid.org/0000-0003-1602-5205

\section{Acknowledgments}

This study was financially supported by the Science and Technology Guidance Project of Jiangu Housing and Urban-Rural Development Department in China (2020ZD001203). Many Thanks to Professor Guangyin Du for his suggestion to the analysis and discussion of this paper. Great thanks also go to the editorial board and the reviewers of this paper. 


\title{
1 A Case Study of Vacuum Tube-well Dewatering Technology
}

\section{2 for Improving Deep Soft Soil in Yangtze River Floodplain}

3

\author{
Biao Zeng ${ }^{1,2}$, Yu Zhen ${ }^{3}$, Dingwen Zhang ${ }^{1,2 *}$, Tao Meng ${ }^{4}$, Zejia Gong ${ }^{1}$, Songyu Liu ${ }^{1}$ \\ 1 School of Transportation, Southeast University, Nanjing, Jiangsu Province 211189, China; \\ 2 National Demonstration Center for Experimental Road and Traffic Engineering Education (Southeast \\ University), Nanjing, Jiangsu Province 211189, China; \\ 3 Nanjing Darcy Geotechnical Engineering Co., Ltd., Nanjing; Jiangsu Province 210041, China; \\ 4 China Tiesiju Civil Engineering Group Co., Ltd., Hefei; Anhui Province 230022, China; \\ * Correspondence: zhangdw@seu.edu.cn
}

\begin{abstract}
Deep soft soil of the Yangtze River floodplain in Nanjing has a special interlayer structure, which provides favorable conditions for the application of vacuum tube-well dewatering technology. This paper focuses on the design, construction and treatment effect of vacuum tube-well dewatering technology. The hydrological parameters and the hydraulic connections between the various layers of the site have been ascertained through two simple single-well multi-holes pumping tests. Moreover, the layout of vacuum tube-wells and depressurization wells in a test site with $84 \mathrm{~m}$ length and $84 \mathrm{~m}$ width was designed based on the above parameters. Field tests of vacuum tube-well dewatering technology were conducted on the test site. And the changes of groundwater level, ground settlement and pore water pressure during the test was monitored. The CPTU test technology was used to quickly evaluate the engineering properties of the site before and after treatment. Finally, combined with the settlement monitoring data, the hyperbolic method was used to predict the final settlement. The results indicated that consolidation efficiency of vacuum tube-well dewatering technology has obvious advantages. Implications of this study can provide a reference for the construction design of the site's ground improvement consolidation and other similar projects.
\end{abstract}

Keywords: vacuum tube-well · pumping test ground settlement · water drawdown level· CPTU. Yangtze River Floodplain

\section{Introduction}

In the downstream reaches of the Yangtze River, the sedimentary particles range from coarse to fine owing to the separation of water flow, making the soft soil in this region have the characteristics of silt clay mixed with fine sand (Iqbal et al. 2005; Cai et al. 2017). In addition to high water content, high compressibility, low shear strength, and low permeability coefficient, this kind of soil is often buried deep, and the underlying sand layer is hydraulically connected to the Yangtze River (Xia et al. 2006; Shi et al. 2016). The engineering geological conditions are extremely complicated. With the advancement of the Yangtze River Economic Belt strategy in China, engineering construction is increasing on the floodplain of the Yangtze River. The foundation treatment project of this kind of soil has become a research hotspot of engineers.

At present, vacuum preloading method is one of the most popular methods for soft clay and dredger fill in coastal and riverside areas (Ding et al. 2019; Griffin and O'Kelly 2014). However, vacuum 
preloading method takes a long time to process, and vacuum degree will attenuate along with depth, which causes its effective depth to be limited (Indraratna 2010; Chai 2005; Shen et al. 2013). Besides, vacuum preloading method will cause fine-grained soil to move around the PVD board and cause blockage, making its performance worse than expected (Wang et al. 2017; Lei et al. 2017; Wang et al. 2016).

In the traditional tube-well dewatering method, the pump are set at the bottom of the wells. The water is pumped up from the bottom through a pipe to a discharge point(Han 2015; Sargent et al. 1998). The method is suitable for the layers with abundant underground aquifers and large soil permeability $(>$ $1.2 \times 10^{-3} \mathrm{~cm} / \mathrm{s}$ ) (Cashman and Preene 2020; Zhang 2017). The application of vacuum technology in tube-well can solve the problem of impermeable aquifer and interlayer stagnant water, and expand the application scope of tube-well dewatering. Vacuum tube-well technology reduces the pore water pressure by pumping groundwater, and increases the effective stress of the soil, thereby improving the strength of the foundation (Han 2015). Vacuum tube-well technology not only retains the advantages of tube-well dewatering, such as large dewatering depth and fast dewatering speed, but also can increase negative pressure in any well section according to formation conditions and engineering needs to absorb saturated water in cohesive soil and residual water at the interface. In principle, it is applicable to the above-mentioned deep sand-clay in the Yangtze River Floodplain.

Many scholars have researched the treatment mechanism and influencing factors of vacuum tube-well technology through theoretical analysis (Shen and Xu 2011; Indraratna et al. 2005; Wu et al. 2016), field tests (Pan 2016; Ren 2011), and numerical simulation (Ahmad et al. 2019; Luo et al. 2008). Rujiliatkamjorn et al. (2007) gave an analytical solution of the consolidation settlement of vacuum-assisted vertical and horizontal drainage. Huang (2014) used regression analysis method, grey forecasting method and neural network method to predict the settlement of vacuum tube-well field experiment, and an effective stress model for steady seepage of saturated soil under vacuum conditions is established. Nie et al. (2014) analyzed of the impact of a single row of well-point spacing on the treatment effect and found that after shortening the pumping well spacing, the dewatering effect was significantly improved. Indraratna et al. (2000) developed an equal plane strain model to perform numerical simulation analysis on tube-well drainage. Vertical tube-wells significantly increased the soil settlement rate, improved the dissipation of pore water pressure, and reduced the lateral deformation of soft clay foundations. Jia et al. (2014) established a three-dimensional groundwater flow model to divide the seepage field of groundwater around a vacuum well-point into a vacuum disturbance zone, a joint influence zone of vacuum and gravity, and a gravity influence zone. Currently, vacuum tube-well technology is mainly used for foundation pit dewatering, and its application in soft foundations is generally used as an auxiliary dewatering method combined with other foundation treatment methods (Liu et al. 2016; Liu et al. 2009). This method is still less applied in the treatment of large-area deep soft foundation in the Yangtze River floodplain, and its treatment performance lacks field test verification.

This study uses two single-well multi-holes pumping tests to prove the hydrogeological conditions and hydraulic connection of the site in the Yangtze River Floodplain. Then the foundation was consolidated by vacuum tube-well dewatering technology. The groundwater level, pore water pressure, ground settlement, combined with CPTU in-situ testing technology, evaluated the site's bearing capacity and physical and mechanical indexes before and after treatment. The research results can provide a 
reference for the construction design of the site's ground improvement consolidation and other similar projects.

\section{Ground conditions and soil characterization}

This site of field test is shown in Fig.1. The westernmost part of the site is about 400m away from the Yangtze River. The landform of the site is alluvial floodplain on the edge of terrace, and the soft soil is widely distributed. To reduce post-construction settlement, the soft soil needs to be treated to accelerate its consolidation. According to the results of drilling exploration, the engineering geological section map of the site is shown in Fig.2(a), and the main physical and mechanical indicators of the rock and soil layers are shown in Table 1. The CPT and SPT profiles to a depth of $30 \mathrm{~m}$ of the test site are presented in Fig.2(b) and Fig.2(c), respectively.

Through the analysis of soil samples of different layer, it is found that the soft soil layer of the site has a special structure. The clay layer is sandwiched with a thin layer of silt sand, and obvious horizontal thin bedding is formed (Fig.2(d)). In layer 2-(2), this structure is particularly obvious. These silt sand interlayers become channels for the horizontal movement of groundwater, which is beneficial to lower the groundwater level and reduce pore water pressure. However, the tube-well dewatering belongs to the category of gravity drainage, and its suction height is limited to a certain extent. It is more suitable for soils with larger permeability coefficients rather than soft clay. By pumping a vacuum in the tube-well to form a negative pressure, it can accelerate the movement of groundwater in the interlayer to the tube-well and solve the above problems.

Table 1 Basic physical and mechanical properties of soil

\begin{tabular}{|c|c|c|c|c|c|c|c|c|c|c|}
\hline soil layer & type of soil layer & $w(\%)$ & $\gamma\left(\mathbf{k N} / \mathbf{m}^{3}\right)$ & $e$ & $I_{L}$ & $I_{\mathbf{P}}$ & $\alpha_{1-2}(\mathbf{M P a})^{-1}$ & $E \mathbf{S 1 - 2}(\mathrm{MPa})$ & $C_{\mathrm{k}}(\mathbf{k P a})$ & $\Phi_{\mathbf{k}}\left({ }^{\circ}\right)$ \\
\hline 1-(1) & new fill & & & & & & & & & \\
\hline 2-(1) & silt-clay & 38.40 & 17.63 & 1.10 & 1.13 & 13.40 & 0.70 & 3.10 & 11.90 & 8.90 \\
\hline 2-(2) & silt sand-clay & 37.10 & 18.03 & 1.04 & 1.10 & 10.32 & 0.64 & 3.32 & 11.80 & 10.30 \\
\hline 3-(1) & sand-silt & 23.1 & 18.87 & 0.730 & 0.87 & 9.6 & 0.51 & 10.86 & 5.53 & 28.6 \\
\hline 3-(2) & clay-sand & 35.70 & 17.65 & 1.05 & 1.09 & 12.40 & 0.59 & 3.51 & 11.50 & 10.60 \\
\hline 4-(1) & strongly weathered andesite & \multicolumn{9}{|c|}{ saturated uniaxial compressive strength of rock $f_{\mathrm{rk}}=0.91 \mathrm{MPa}$ (standard value) } \\
\hline 4-(2) & weathered andesite & \multicolumn{9}{|c|}{ saturated uniaxial compressive strength of rock $f_{\mathrm{rk}}=9.91 \mathrm{MPa}$ (standard value) } \\
\hline
\end{tabular}

Note: $w$-moisture content; $\gamma$ - unit weight; $e$-void ratio; $I_{\mathrm{L}}$-liquidity index; $I_{\mathrm{P}}$-plasticity index;

$\alpha_{1-2}$-compressibility coefficient; $E_{\mathrm{s} 1-2}-$ compression modulus; $C_{\mathrm{k}}-$ cohesion; $\Phi_{\mathrm{k}}$-friction angle

The types of groundwater in the site are mainly pore phreatic water and micro-confined water that occur in the Quaternary loose layer. The phreatic aquifers include layer 2-(1) and layer 2-(2). The layer 3-(1) is confined aquifer, which has a certain hydraulic connection with the upper phreatic water and is the vertical replenishment source for the upper soft soil layer. After the confined water level is reduced, the replenishment of the upper soft soil layer is effectively reduced, and the groundwater in the soft soil layer can penetrate into the lower silt fine sand layer through the crisscross interlayer, which accelerates the consolidation and settlement of the upper soft soil. The main sources of phreatic water replenishment are atmospheric precipitation and surface runoff, and the main discharge method is natural evaporation. In the horizontal direction, the confined aquifer ends at about $80 \mathrm{~m} \sim 100 \mathrm{~m}$ outside the site, and beyond the end position is the clay layer. Therefore, the clay layer can be used as a horizontal impermeable boundary, while in the vertical direction, the underlying bedrock is used as impermeable boundary. The buried depth of the first sight water level measured during the exploration 
is $0.5 \mathrm{~m} \sim 3.1 \mathrm{~m}$ below the natural ground, and the stable groundwater depth is $0.6 \mathrm{~m} \sim 3.2 \mathrm{~m}$ below the natural ground, and the elevation is $0.96 \mathrm{~m} \sim 5.0 \mathrm{~m}$. The groundwater level changes seasonally and periodically. According to the hydrogeological data of the Nanjing area, the annual change of the phreatic water level is generally about $2.0 \mathrm{~m}$. The elevation of the confined water level is generally around $3.5 \mathrm{~m}$.

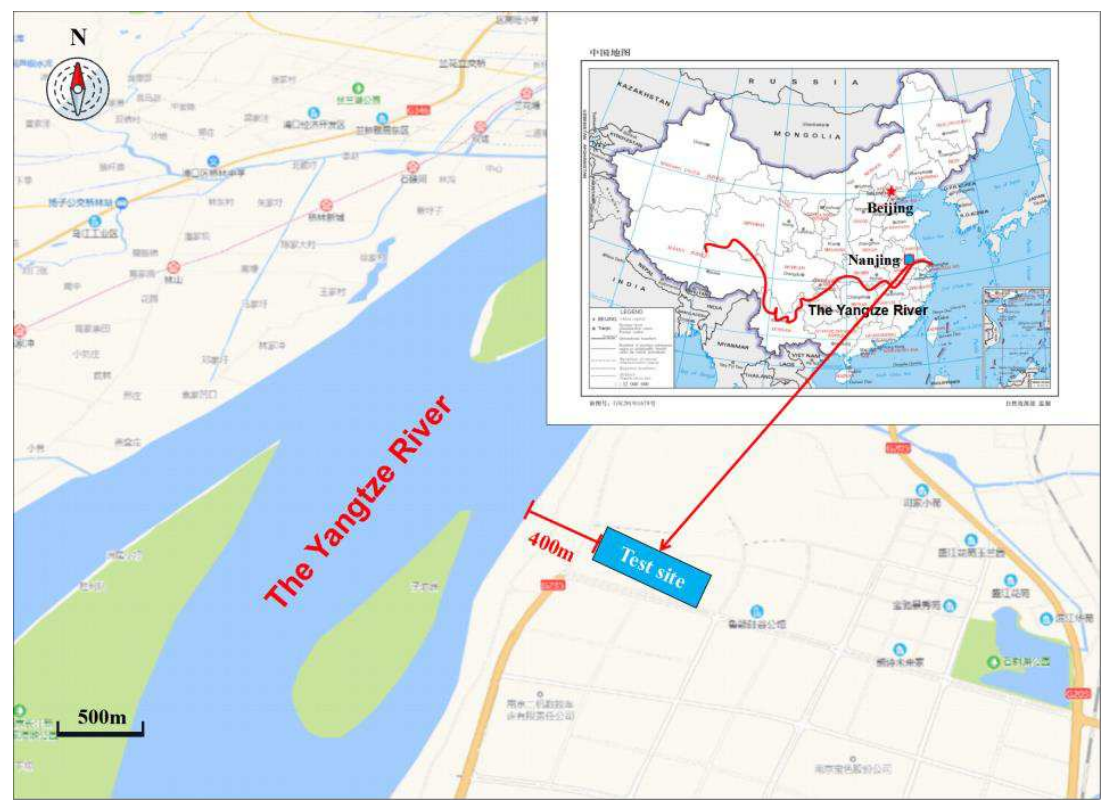

Fig.1. Site location

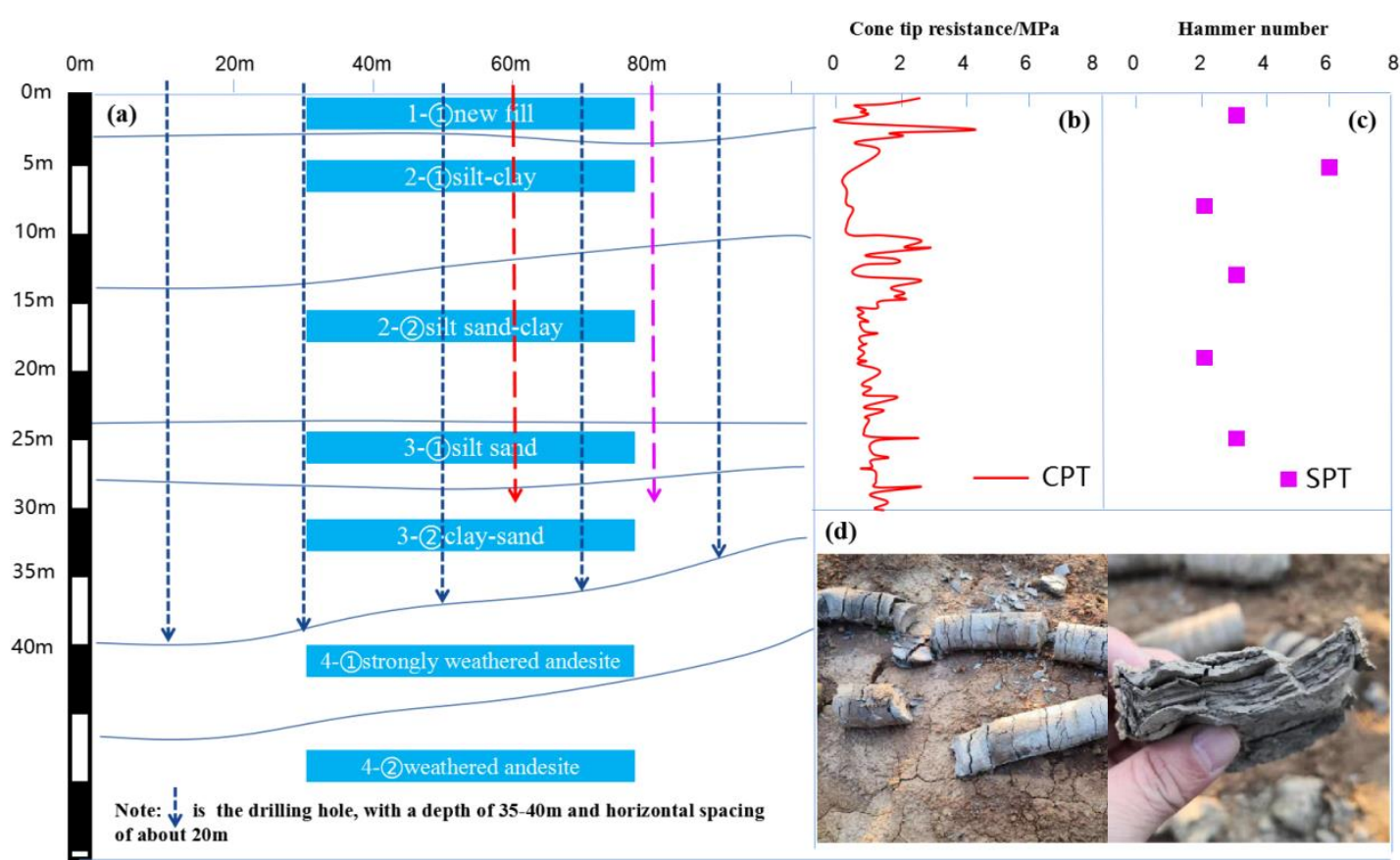

Fig.2 (a) soil layer division; (b) CPT soil profile; (c) SPT soil profile;(d) drilling and coring photos

\section{Single-well multi-holes pumping test and result analysis}

\subsection{Test scheme}

In order to ascertain the permeability, water outflow and water richness of phreatic aquifer and confined aquifer at the test site, and to determine the relevant hydrogeological parameters, as well as 
provide design references for the construction of vacuum tube-well. Two single-well with multi-hole observations tests were conducted on the confined aquifer and phreatic aquifer respectively. The pumping tests adopt reverse circulation rotary drilling to form holes. Then the tube well is put into the hole, clean the side wall of the tube well to prevent blockage. Finally, the filter material (medium-coarse sand) is fixed between the sidewall of hole and the sidewall of tube well. The specific test scheme is as follows:

(1) Confined aquifer: The main pumping well is $\mathrm{ZJ} 01$, the well depth is $27 \mathrm{~m}$, and the well diameter is 273mm. Five observation holes are set simultaneously (GC01, GC02, GC03, GC04, GC05). The arrangement direction of GC01, GC02 is perpendicular to impermeable boundary, while the arrangement direction of GC03, GC04 is parallel to the impermeable boundary. The depth of observation holes is the same as that of the main well. In addition, set the GC05 hole as the phreatic level observation hole with a depth of $22 \mathrm{~m}$, which is used to observe the change of phreatic water level during the extraction of confined water. The specific layout is shown in Fig.3. The single well multi-hole pumping test of confined aquifer started on May 8, 2020. The pumping process lasted for 16 hours. After the pumping was stopped, the water level recovery observation was carried out. The observation time was about 20 hours.

(2) Phreatic aquifer: The main pumping well is ZJ02, the depth of the well is $24 \mathrm{~m}$, and the well diameter is $273 \mathrm{~mm}$. Six monitoring holes are set simultaneously (GC06, GC07, GC08, GC09, GC10, GC11). The depth of the observation holes is consistent with the depth of the main pumping well. The specific layout is shown in Fig.3. The single well multi-hole pumping test started on May 11, 2020. The pumping test lasted for 14hours. After the pumping was stopped, the water level recovery observation was carried out. The observation time was about 6 hours.

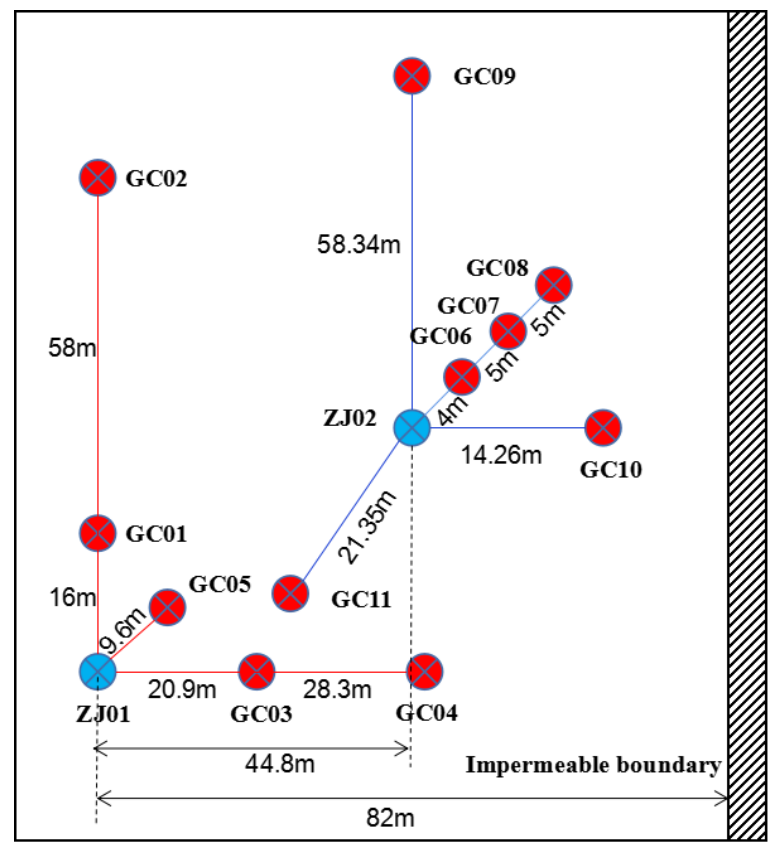

Fig.3 Layout drawing of pumping test.

\subsection{Test results of confined aquifer}

The initial water level elevation of the confined aquifer measured on site is about $3.05 \mathrm{~m} \sim 3.19 \mathrm{~m}$. Fig.4 shows the curve of the water drawdown level of each observation hole with time. In the early stage of pumping, the water drawdown level drops quickly, and after 120 minutes, it starts to slow down. To the 
end of pumping, the water drawdown level of each observation well is between $1.4 \mathrm{~m}$ and $3.87 \mathrm{~m}$. Because hole GC02 is far away from the main well, the water drawdown level is the smallest. However, The GC01, GC03, and GC04 water drawdown levels are relatively close, and one of the GC03 water drawdown level is the most, which is $3.87 \mathrm{~m}$. After the pumping was stopped, the confined water level of the observation wells recovered faster. It shows that the confined aquifer has a certain supply source. In addition, the phreatic observation hole GC05, about 9.6m away from the main pumping well, was observed. During the pumping period, the water drawdown level is $5 \mathrm{~cm}$. After pumping was stopped, the depth of the phreatic aquifer changed from $2.98 \mathrm{~m}$ to $2.91 \mathrm{~m}$, which risen by $7 \mathrm{~cm}$. It can be seen that although the phreatic level changes little during the pumping process, the water level changes are synchronized with the pumping process, indicating that there is a certain hydraulic connection between the phreatic aquifer and the confined aquifer, but the hydraulic connection is very weak and can be ignored in construction.

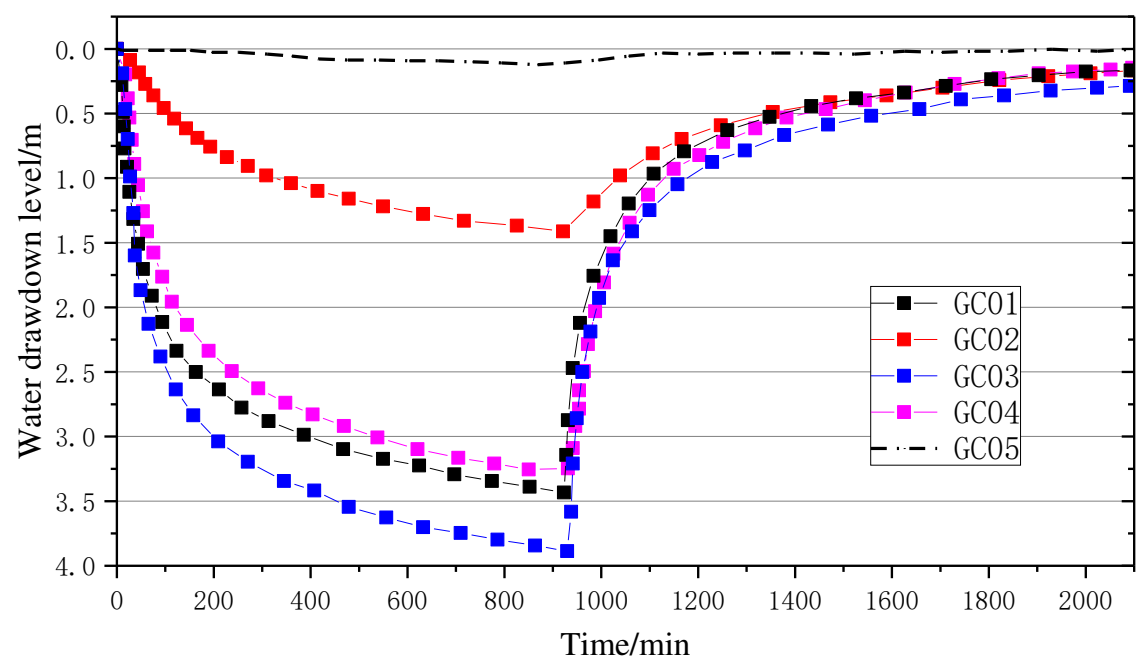

Fig. 4 Curve of water drawdown level of each observation well with time (confined aquifer)

Combined with the water drawdown level data of each observation hole and the monitoring of outflow. According to the hydrogeology manual of China (China Geological Survey Bureau, 2013), using the Eq.(1) Eq.(4) for the complete well in the confined aquifer, the permeability coefficient, transmissibility coefficient and influence radius of the confined aquifer can be obtained. The calculation diagram is shown in Fig.5, and the calculation results are shown in Table 2. After calculation, the permeability coefficient of the confined aquifer is $K \approx 9.38 \sim 13.55 \mathrm{~m} / \mathrm{d}$, the average permeability coefficient $K=11.46 \mathrm{~m} / \mathrm{d}$, the average transmissibility coefficient is $50.42 \mathrm{~m}^{2} / \mathrm{d}$, and the average influence radius is $345 \mathrm{~m}$. 


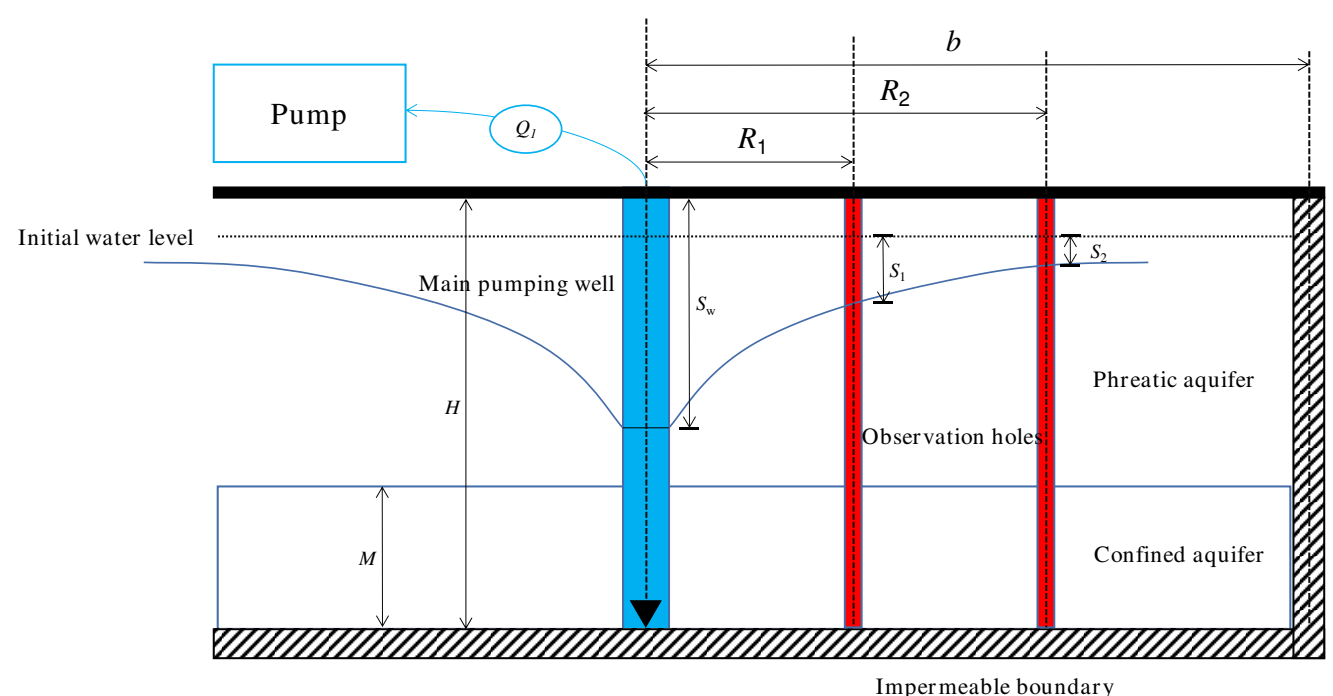

182

183

Fig. 5. Simplified diagram of calculation for water pumping test of confined aquifer

When the observation holes are perpendicular to impermeable boundary,

$$
K=\frac{0.366 Q_{1}}{M\left(S_{1}-S_{2}\right)} \lg \frac{R_{2}\left(2 b-R_{2}\right)}{R_{1}\left(2 b-R_{1}\right)}
$$

When the observation holes are parallel to impermeable boundary,

$$
K=\frac{0.366 Q_{1}}{M\left(S_{1}-S_{2}\right)} \lg \frac{R_{2} \sqrt{\left(4 b^{2}-R_{2}^{2}\right)}}{R_{1} \sqrt{\left(4 b^{2}-R_{1}^{2}\right)}}
$$

$$
R=10 S_{\mathrm{w}} \sqrt{K}
$$

$$
T=K M
$$

Where, $M$ is the thickness of the confined aquifer(m); $S_{1} 、 S_{2}$ are the water drawdown level of the two observation holes $(\mathrm{m}) ; R_{1} 、 R_{2}$ are the center distance between the two observation holes and the pumping well(m); $Q_{1}$ is water outflow of the pumping well( $\left.\mathrm{m}^{3} / \mathrm{d}\right) ; K$ is permeability coefficient $(\mathrm{m} / \mathrm{d}) ; b$

\begin{tabular}{|c|c|c|c|c|c|c|c|c|c|}
\hline direction & number & $R_{1} / R_{2}(\mathrm{~m})$ & $S_{1} / S_{2}(\mathbf{m})$ & $Q_{1}\left(\mathrm{~m}^{3} / \mathrm{d}\right)$ & $b(\mathbf{m})$ & $M(\mathbf{m})$ & $K(\mathbf{m} / \mathbf{d})$ & $R(\mathbf{m})$ & $T\left(\mathbf{m}^{2} / \mathbf{d}\right)$ \\
\hline \multirow[b]{2}{*}{ paraller } & GC01 & 16 & 3.40 & \multirow[b]{2}{*}{365} & \multirow[b]{2}{*}{82} & \multirow[b]{2}{*}{4.4} & \multirow[b]{2}{*}{9.38} & \multirow[b]{2}{*}{378.41} & \multirow[b]{2}{*}{59.60} \\
\hline & GC02 & 74 & 1.40 & & & & & & \\
\hline \multirow[b]{2}{*}{ perpendicular } & GC03 & 20.9 & 3.86 & \multirow[b]{2}{*}{365} & \multirow[b]{2}{*}{82} & \multirow[b]{2}{*}{4.4} & \multirow[b]{2}{*}{13.55} & \multirow[b]{2}{*}{312.36} & \multirow[b]{2}{*}{41.26} \\
\hline & GC04 & 49.3 & 3.24 & & & & & & \\
\hline
\end{tabular}
is the distance of the pumping well from the impermeable boundary $(\mathrm{m}) ; R$ is influence $\operatorname{radius}(\mathrm{m}) ; T$ is transmissibility coefficient $\left(\mathrm{m}^{2} / \mathrm{d}\right) ; S_{\mathrm{w}}$ is water drawdown level of the main pumping well $(\mathrm{m})$.

Table 2 Test results of confined aquifer 


\subsection{Test results of phreatic aquifer}

The initial water level of the phreatic aquifer measured on site is about $5.66 \mathrm{~m} \sim 5.837 \mathrm{~m}$. Fig. 6 shows the curve of the water drawdown level of each observation hole with time. The variation trend of this curve is similar to the confined aquifer. However, from the depth of water drawdown, each observation hole in the phreatic aquifer is lower than that of the confined aquifer. After pumping, the water drawdown level in each observation hole is between $0.21 \mathrm{~m}$ and $1.56 \mathrm{~m}$. One of the observations well GC06, which is closer to the main well $(4.31 \mathrm{~m})$, it has the largest water drawdown level of $1.56 \mathrm{~m}$. It indicates that the water permeability of the phreatic aquifer is less than the confined aquifer. In addition, the observation hole GC08, which is far away from the main well $(58.34 \mathrm{~m})$, has a water drawdown level of $0.21 \mathrm{~m}$, and still retains a certain downward trend, reflecting that the phreatic aquifer has a certain permeability and range of influence.

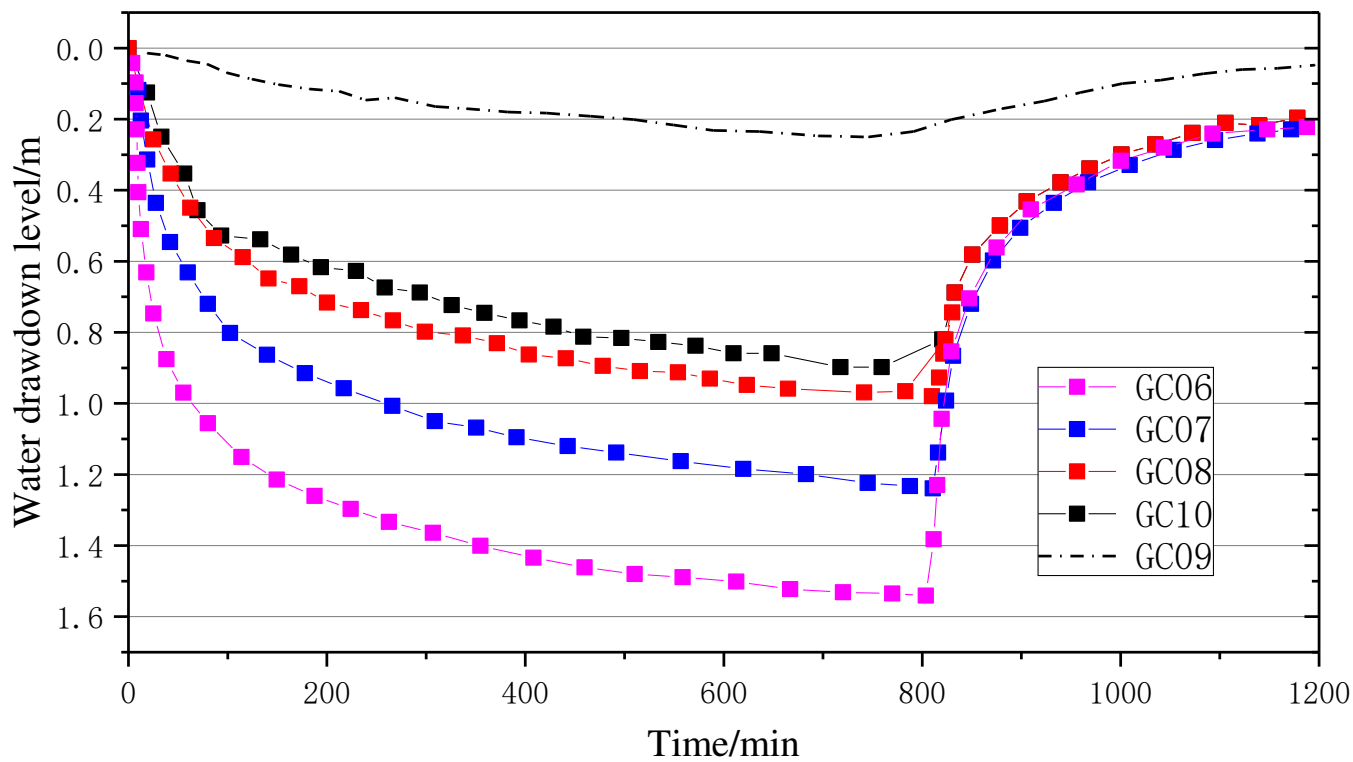

Fig.6 Curve of water drawdown level of each observation well with time (phreatic aquifer)

Similarly, using Eq.(5) and Eq.(6) for complete wells in phreatic aquifers, the permeability coefficient and influence radius are calculated. The calculation diagram is shown in Fig.7, and the calculation results are shown in Table 3. From the results, the permeability coefficient of the phreatic aquifer is $K=0.76 \mathrm{~m} / \mathrm{d} \sim 1.05 \mathrm{~m} / \mathrm{d}$, the average permeability is $\mathrm{K}=0.86 \mathrm{~m} / \mathrm{d}$, and the influence radius is about $81 \sim 244 \mathrm{~m}$. Due to the large difference in the calculated influence radius, the graphic method (Han 2015) is applied to find influence radius as shown in Fig.8. This method uses the curve between water drawdown level and distance to connect and extend. When the water drawdown level to zero, the corresponding distance is the influence radius. According to Fig.8, it is recommended that the influence radius of the phreatic aquifer is $130 \mathrm{~m}$. 


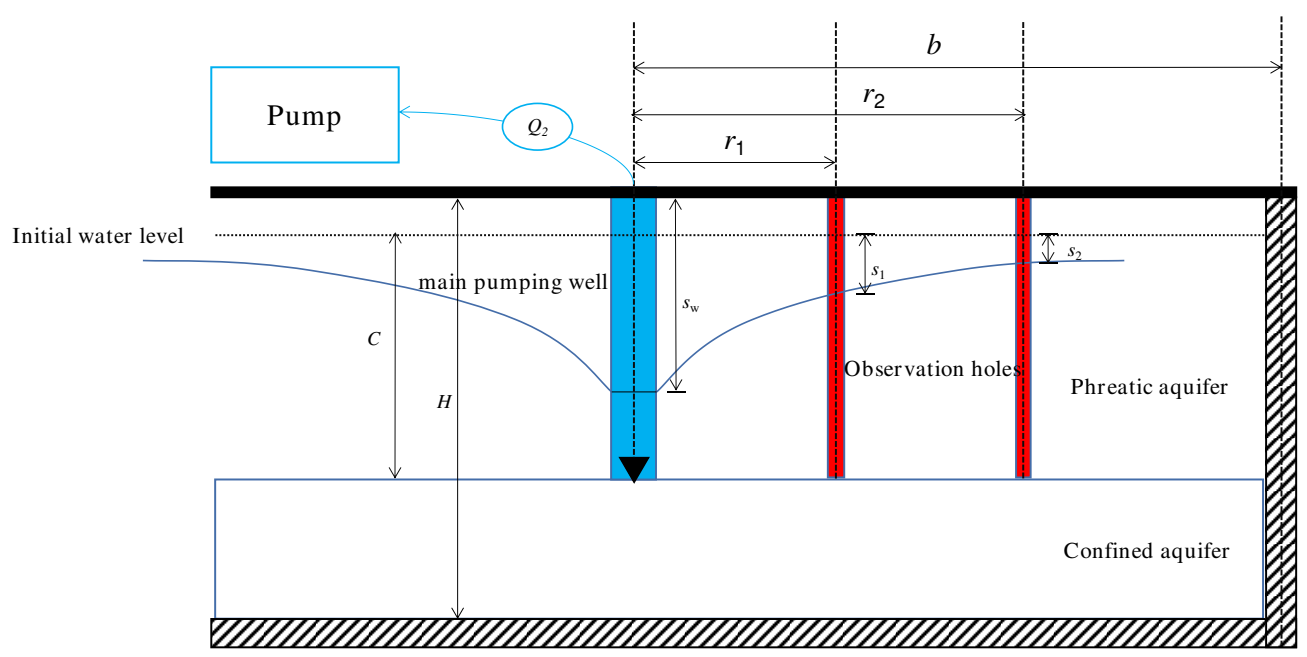

$$
K=\frac{0.733 Q_{2}\left(\lg r_{2}-\lg r_{1}\right)}{\left(2 C-s_{1}-s_{2}\right)\left(s_{1}-s_{2}\right)}
$$

$$
\lg R=\frac{s_{1}\left(2 C-s_{1}\right) \lg r_{2}-s_{2}\left(2 C-s_{2}\right) \lg r_{1}}{\left(2 C-s_{1}-s_{2}\right)\left(s_{1}-s_{2}\right)}
$$

229 Where, $\mathrm{C}$ is the thickness of the phreatic aquifer(m); $s_{1}$ and $s_{2}$ are the water drawdown level of the two 230 observation holes $(\mathrm{m}) ; r_{1}$ and $r_{2}$ are the center distance between the two observation holes and the 231 pumping well(m); $Q_{2}$ is water inflow of pumping well( $\left.\mathrm{m}^{3} / \mathrm{d}\right) ; K$ is permeability coefficient $(\mathrm{m} / \mathrm{d})$.

Table 3 Test results of phreatic aquifer

\begin{tabular}{cccccccc}
\hline group & number & $\boldsymbol{r}_{1} / \boldsymbol{r}_{2}(\mathbf{m})$ & $\boldsymbol{s}_{1} / \mathbf{s}_{2}(\mathbf{m})$ & $\boldsymbol{Q}_{2}\left(\mathbf{m}^{3} / \mathbf{d}\right)$ & $\boldsymbol{C}(\mathbf{m})$ & $\boldsymbol{K}(\mathbf{m} / \mathbf{d})$ & $\boldsymbol{R}(\mathbf{m})$ \\
\hline \multirow{2}{*}{1} & GC06 & 4.0 & 1.56 & & 21 & 1.05 & 244 \\
& GC07 & 9.0 & 1.24 & 51.48 & & & \\
2 & GC06 & $4 . .0$ & 1.56 & & 21 & 0.86 & 117 \\
& GC08 & 14.0 & 0.98 & 51.48 & & & \\
3 & GC06 & 4.0 & 1.56 & & & & \\
& GC10 & 14.26 & 0.91 & 51.48 & & & \\
4 & GC06 & 4.0 & 1.56 & & 21 & 0.76 & 88 \\
\hline
\end{tabular}




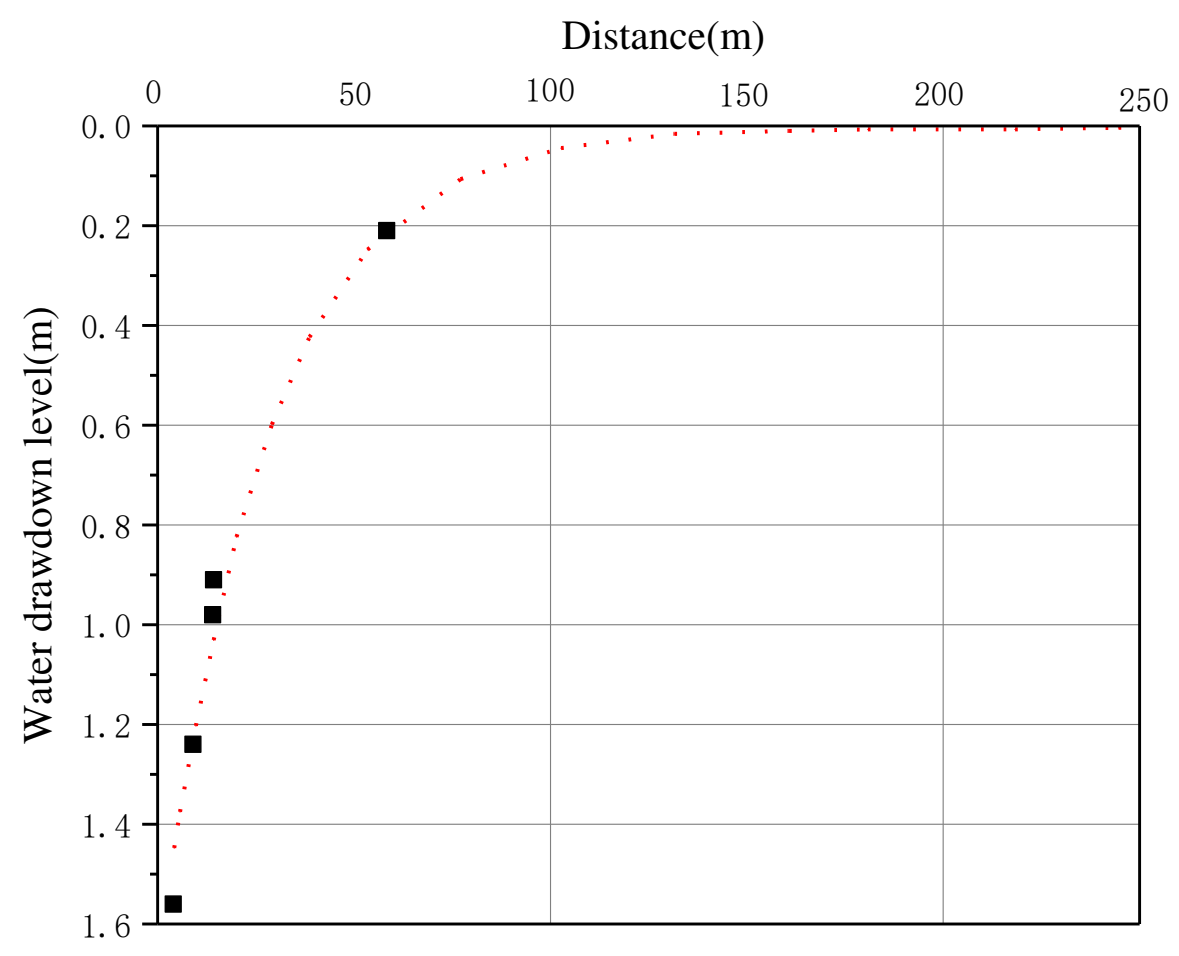

Fig.8 Graphic Method

In summary, according to the pumping test, the hydrogeological parameters and hydraulic connections of the confined water layer and the phreatic layer were obtained, which can provide design basis for the layout, number, and spacing of the decompression wells and vacuum tube-wells.

\section{Field Test of Vacuum Tube-well Technology}

In order to analyze the feasibility of vacuum tube-well dewatering technology for improving the soft soil in Yangtze River floodplain. An area with $84 \mathrm{~m}$ long and $84 \mathrm{~m}$ wide was selected for the field test. Through monitoring groundwater level, surface subsidence, pore water pressure, combined with CPTU in-situ testing technology to summarize and evaluate the treatment performance.

\subsection{Test scheme}

In the construction of tube-well dewatering, the layout of dewatering wells is of great significance to the treatment effect. The number of dewatering wells can be calculated according to total outflow of the site and the outflow of single dewatering well. The specific calculation method is shown in Eq.(7) Eq.(10). (Ministry of Housing and Urban-Rural Development of China 2016; Han 2015)

$$
n=\lambda Q / q
$$

Where, $n$ is the number of dewatering wells; $Q$ is the total outflow $\left(\mathrm{m}^{3} / \mathrm{d}\right) ; q$ is the outflow of single well $\left(\mathrm{m}^{3} / \mathrm{d}\right) ; \lambda$ is the adjustment coefficient, taken as 1.2 .

For phreatic well (dewatering for phreatic aquifer), The total outflow includes recharge $Q_{\mathrm{r}}$ and static reserves $Q_{\text {s. }}$.

$$
Q_{r}=\pi K \frac{\left(2 C-S_{\mathrm{d}}\right) S_{d}}{\operatorname{In}\left(1+\frac{R}{r_{0}}\right)}
$$




$$
Q_{\mathrm{s}}=A S_{w} \mu / t
$$

\section{0}

261

Where, $r_{0}$ is equivalent radius, $r_{0}=\sqrt{A / \pi}(\mathrm{m}) ; A$ is field area $\left(\mathrm{m}^{2}\right) ; \mu$ is yield of water, taken as 0.1 according to experience; $t$ is design dewatering time(d); $S_{\mathrm{d}}$ is design dewatering $\operatorname{depth}(\mathrm{m}) ; C$ is the thickness of the phreatic aquifer(m).

For depressurization well (dewatering for confined aquifer), the total outflow can be calculated as follow,

$$
Q=2 \pi K \frac{M S_{\mathrm{d}}}{\operatorname{In}\left(1+\frac{R}{r_{0}}\right)}
$$

Where, $M$ is the thickness of the confined aquifer(m); $K$ is permeability coefficient(m/d).

The field test site is an area with $84 \mathrm{~m}$ long and $84 \mathrm{~m}$ wide. With reference to the calculation results of the single-well multi-hole pumping test, combined with Eq. (7) Eq. (10), the number of phreatic wells and depressurization wells in the site can be obtained. The calculation results are shown in Table.4.

\begin{tabular}{ccccccccccccc}
\multicolumn{10}{c}{ Table 4 Design and calculation results of drainage wells } \\
\hline types of well & $\boldsymbol{A}\left(\mathbf{m}^{2}\right)$ & $\boldsymbol{C} / \boldsymbol{M}(\mathbf{m})$ & $\boldsymbol{S}_{\mathbf{d}(\mathbf{m})}$ & $\boldsymbol{R}(\mathbf{m})$ & $\boldsymbol{r}_{\mathbf{0}}(\mathbf{m})$ & $\boldsymbol{t}(\mathbf{d})$ & $\begin{array}{c}\boldsymbol{Q}_{\mathbf{r}} \\
\left(\mathbf{m}^{3} / \mathbf{d}\right)\end{array}$ & $\begin{array}{c}\boldsymbol{Q}_{s} \\
\left(\mathbf{m}^{3} / \mathbf{d}\right)\end{array}$ & $\begin{array}{c}\boldsymbol{Q} \\
\left(\mathbf{m}^{3} / \mathbf{d}\right)\end{array}$ & $\boldsymbol{n}$ \\
\hline phreatic well & 7056 & 21 & 15 & 130 & 47.5 & 20 & 829 & 529 & 1493 & 33 \\
Depressurization well & 7056 & 4.4 & 15 & 345 & 47.5 & 20 & $/$ & $/$ & 2248 & 9 \\
\hline
\end{tabular}

Based on the above calculation results, while considering the graphic design. The phreatic wells are arranged in a square shape with a spacing of $14 \mathrm{~m}$, a total of 36 . In addition, a set of $7 \mathrm{~m}$ spacing and a set of $5 \mathrm{~m}$ spacing are arranged in the field for comparison, which can compare the influence of different well spacing on the effect of dewatering and consolidation. It is important to note that seven wells of SG01 SG05, SG08, and SG15 use no-vacuum tube-wells, and the remaining phreatic wells use vacuum tube-wells. Depressurization wells are arranged in the outer circle of the field with a spacing of $28 \mathrm{~m}$, a total of 12 . The number of depressurization wells is slightly higher than the calculation result, mainly because the site is located around the Yangtze River and the hydraulic connection is more complicated. Therefore, several depressurization wells have been added to ensure the treatment effect. The layout of wells in the site are shown in Fig.9 


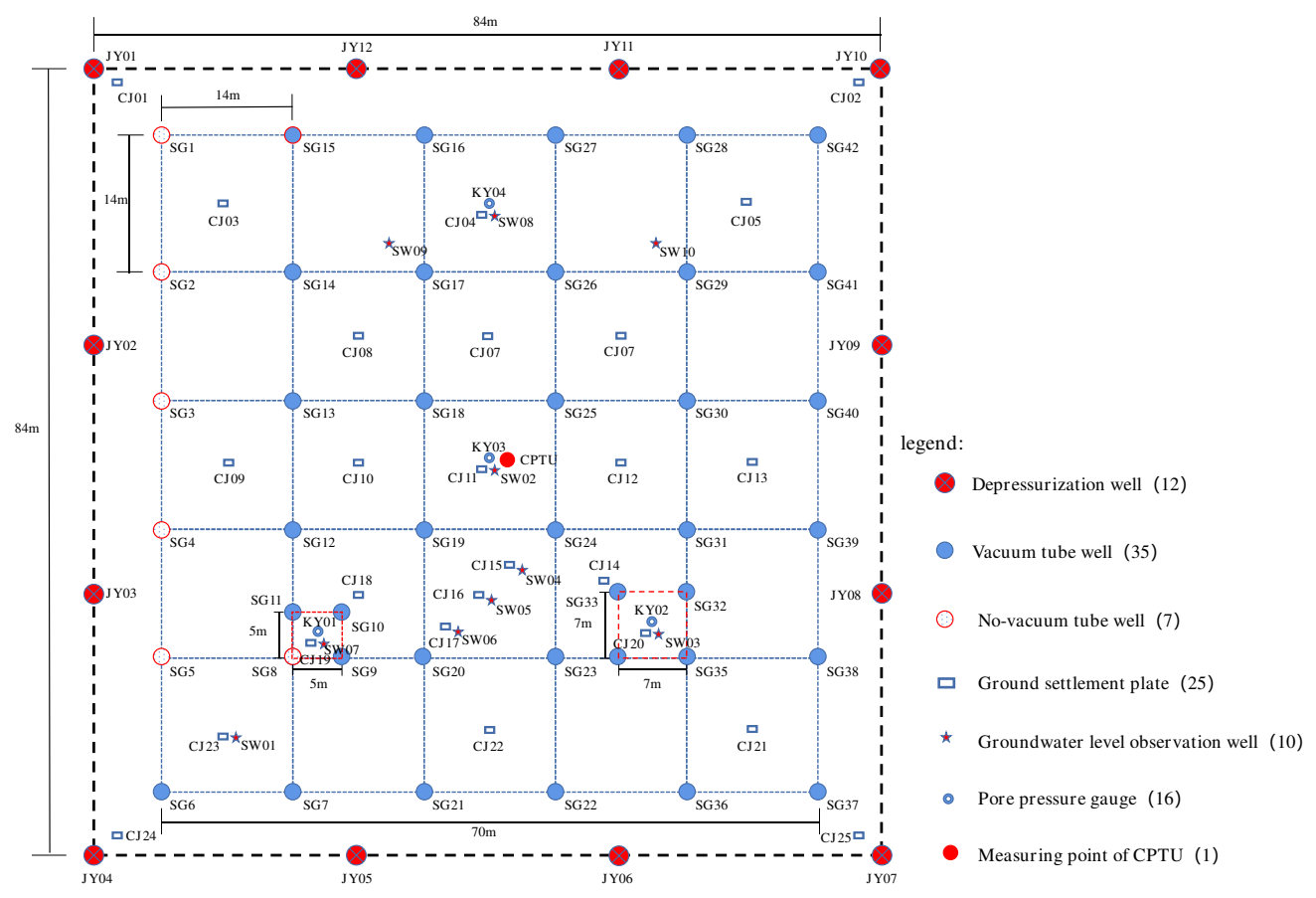

Fig. 9 The layout of the site and the location of each monitoring point

The construction of the vacuum tube-well is carried out according to the following steps. Firstly, reverse circulation drilling is used to form the hole with a diameter of $450 \mathrm{~mm}$ (Fig.10(a)). Subsequently, the suspension method is used to put in the vacuum tube-well. (Fig.10(b)). The vacuum tube-well is proposed to use a steel pipe with a diameter of $273 \mathrm{~mm}$ (outer diameter). The steel pipe has filter holes in the aquifer. And the holes are wrapped with a 60 mesh nylon filter. The depth of the vacuum tube-well is about $24 \mathrm{~m}$. After the vacuum tube-well is fixed, immediately backfill the filter material (Fig.10(c)). The filter material used is medium-coarse sand. Finally, use a pump to wash the well until the well water reaches the specification requirements (Fig.10(d)). The upper part 3m-4m of wells is sealed with cement slurry and a sealing cap on the top of the well to ensure the vacuum condition in the well. Four vacuum tube-wells share a vacuum pump as shown in Fig.11. In the early stage of dewatering operation, vacuum pump is applied to the dewatering well, and the vacuum degree is not less than $60 \mathrm{kPa}$. Vacuum pumping is performed alternately with a vacuum pump and a submersible pump. The pumping interval of the submersible pump ranges from short to long. Each time the water in the dewatering well is drained, the pump is stopped immediately. For wells with a large amount of water, the number of pumping times per day will increase accordingly. The opening and closing of the submersible pump are controlled automatically.

The construction steps of depressurization wells are similar to those of the vacuum tube-wells, except that the pump of the depressurization wells is arranged in the confined aquifer, so its length is about $27 \mathrm{~m}$. And the upper part of wells depressurization is sealed with clay slurry. The permeability coefficient of the confined aquifer is large, so vacuum pumps are not used.

Arranging ground settlement plates, layered settlement holes, groundwater level observation wells, pore pressure gauges at different locations on the site. And use the CPTU test vehicle to test the changes in the soil engineering properties before and after the treatment. The layout of the site and the location of each monitoring point are shown in Fig. 9. 

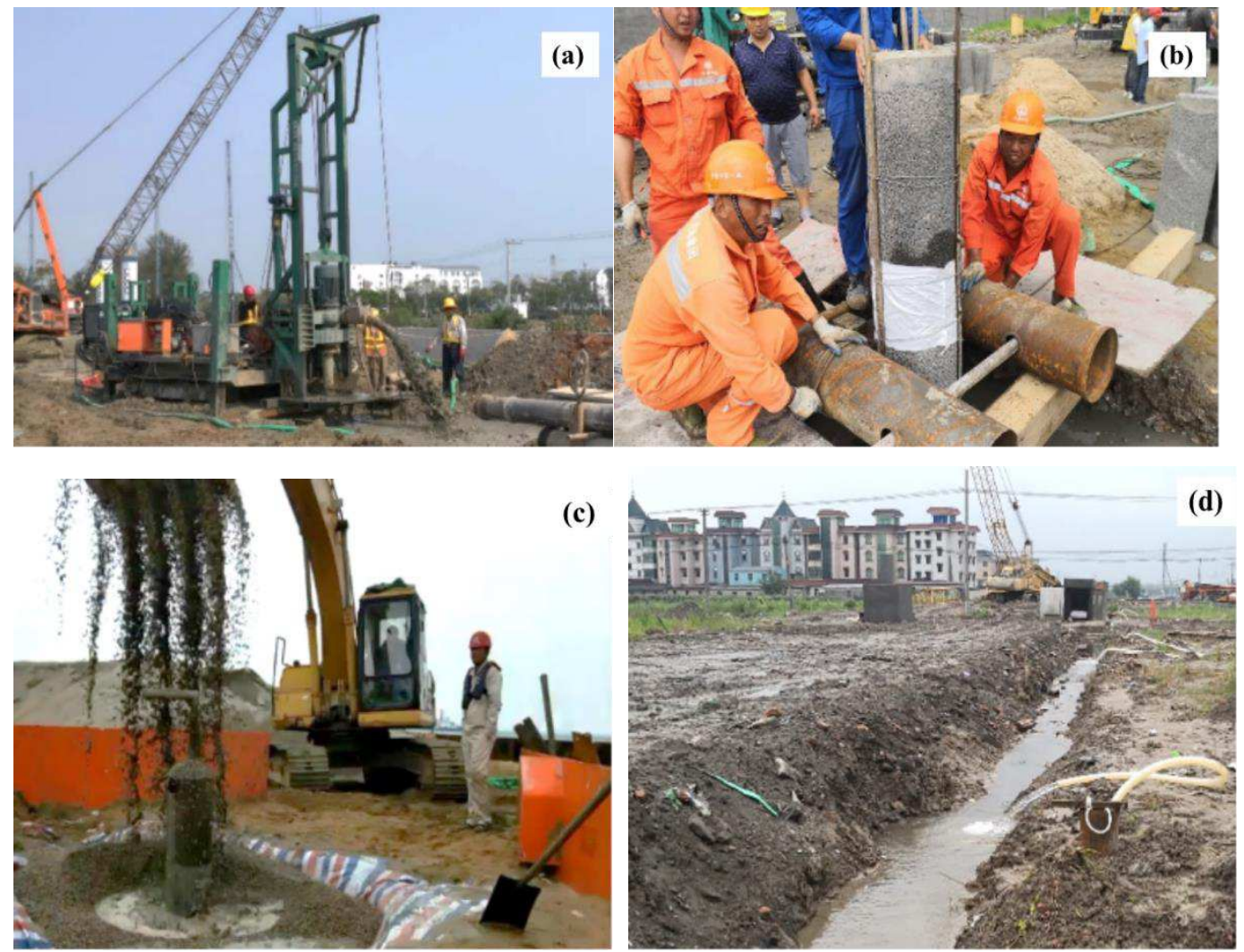

Fig.10. (a) Drilling holes by reverse circulation; (b) Insert the tube-well;

(c) Backfill filter material;(d) Clean the tube-well and test pumping

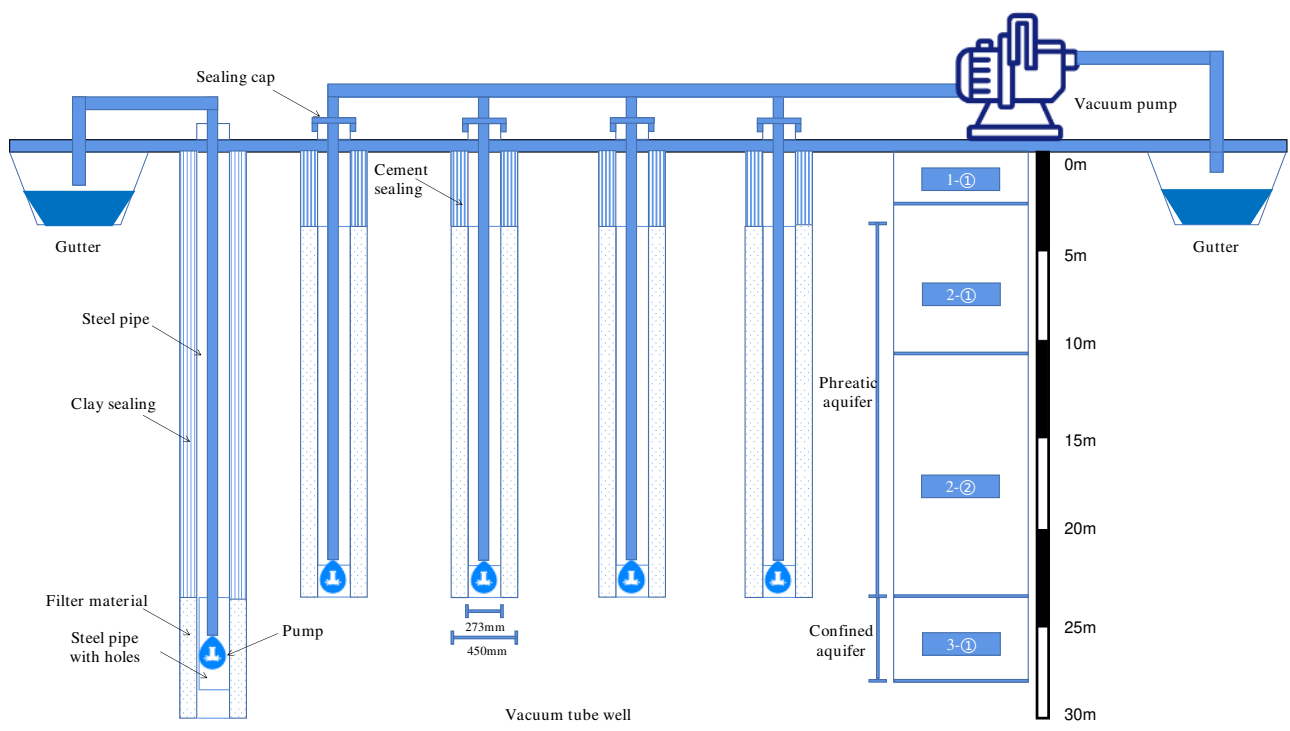

Fig.11 Structure and connection of wells

\section{(1) CPTU field test}

Use the in-situ CPTU technology to test the soil properties before and after the reinforcement. CPTU test adopts SEU@CPTU-2 digital multi-function CPTU holes pressure static penetration probe system, equipped with multi-function digital probe. Not only can measure the cone tip resistance $q_{\mathrm{c}}$ and sidewall friction $f_{\mathrm{s}}$, but also the pore water pressure $u$ and the dissipation process of excess pore water pressure in the soil layers below the groundwater level can be tested (Cai et al. 2009). 
The groundwater level observation well is mainly used to observe the drop of the phreatic level (water level of the soft soil layer) in the test site. Ten observation wells are arranged in different positions in the site. The water level observation well has a depth of $24 \mathrm{~m}$, a diameter of about $450 \mathrm{~mm}$, and a double-walled corrugated pipe with a diameter of $250 \mathrm{~mm}$.

\section{(3) Ground settlement plate}

Ground settlement plates are used to monitor changes during the processing. A total of 25 ground settlement was set up and buried in the undisturbed soil, evenly distributed around and in the middle of the site.

\section{(4) Pore water pressure gauges}

Pore water pressure gauges are used to monitor changes in pore pressure during treatment. The pore water pressure gauges are buried in the center of the tube-wells with different spacing, divided into three groups, and an additional group is added at the center of the site, each group has 4, a total of 16, and the buried depths are $15 \mathrm{~m}, 20 \mathrm{~m}, 25 \mathrm{~m}$, and $30 \mathrm{~m}$.

The monitoring instruments were buried in accordance with the test plan, the initial values were collected, and the CPTU data of the in-situ soil was measured. The field test began on the morning of May 23 and ended on June 11 for a total of 20 days. During the pumping process, the ground settlement, groundwater level, and pore water pressure are monitored. After the pumping is completed, the treated soil is tested again with CPTU.

\subsection{Ground settlement}

Fig.12 shows the variation curve of cumulative ground settlement over time for some typical monitoring points. It can be seen that as the groundwater is pumped out, the surface settlement gradually increases. This is mainly because the pore water pressure of the soil decreases and the effective stress increases, which causes the soil to consolidate. Among the monitoring points, CJ20 has the largest surface subsidence at $726 \mathrm{~mm}$, which is located at the center of the well spacing of $7 \mathrm{~m}$. CJ19, which is located at the center of the $5 \mathrm{~m}$ well spacing, and its settlement is $597 \mathrm{~mm}$. The settlement of the site center CJ11 point is $628 \mathrm{~mm}$. The average ground settlement within the diving well group is about $611 \mathrm{~mm}$.

The contour map of the ground settlement of the test site is shown in Fig.13. The settlement of the entire site decreases radially from the center to the surrounding with $7 \mathrm{~m}$ spacing wells. It is generally believed that after shortening the spacing of pumping wells, the dewatering effect will be significantly improved. However, the settlement of the tube-well spacing of $7 \mathrm{~m}$ is greater than that of $5 \mathrm{~m}$ in this site. This is mainly because each tube-well has a dewatering influence range. When the distance between the tube wells is too large, the dewatering treatment range is limited; when the distance between the tube-wells is too small, the mutual interference of the vacuum zones between different tube-wells inhibits the dewatering effect. Therefore, there is an optimal spacing for the vacuum tube-well dewatering method. On this site, the space of $7 \mathrm{~m}$ is better.

Another observation is that the settlement on the left side of the test site is relatively small, which is believed to be related to the lack of vacuum pumping in nearby submersible wells. Vacuum tube-well dewatering can form negative pressure around the pipe inlet, accelerate pumping, reduce pore water pressure in the soil, and increase pumping rate and consolidation efficiency. 


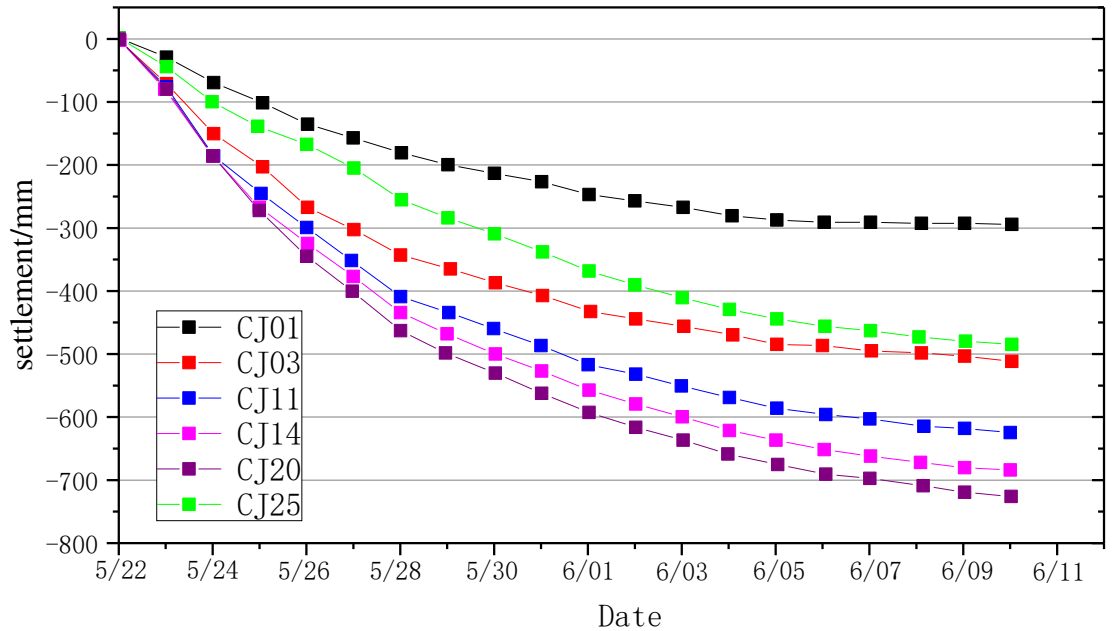

Fig.12. Variation curve of cumulative ground settlement over time for some typical monitoring points

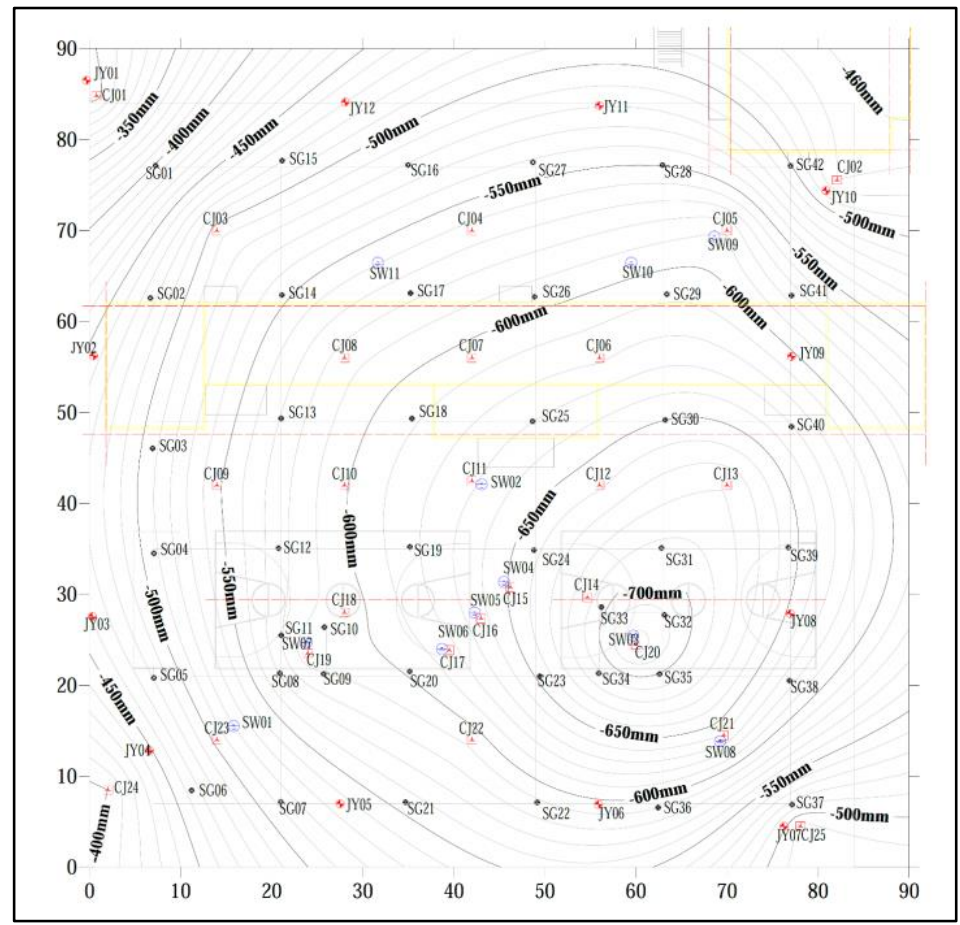

Fig.13. Contour map of the ground settlement

\subsection{Groundwater level}

The groundwater levels at different locations on the site were monitored. Fig.14 shows the variation curves of the groundwater levels at some typical monitoring points with pumping time. As shown in Fig.14, as the pumping continues, the depth of the groundwater level gradually decreases. The phreatic level is basically reduced to the buried depth of $10 \sim 13 \mathrm{~m}$, and the water drawdown levels to about $9 \sim 11 \mathrm{~m}$. Among them, the water level of SW03 drops to a buried depth of $18.6 \mathrm{~m}$, and the water drawdown levels to about $16.7 \mathrm{~m}$. This point is located at the center of the $7 \mathrm{~m}$ well spacing and corresponds to the point CJ20 with the largest amount of ground settlement. However, it is interesting to observe that comparing the water level drawdown curve and the settlement curve, it can be found that the settlement curve is of a "slow drop type", that is, as the groundwater is 
pumped out, the settlement keeps increasing at a slower rate. The water level drawdown curve shows a "steep drop-slow drop type". Initial pumping, the water drawdown levels very quickly, the water level within 24 hours drawdown reduces by about $80 \%$ of the total depth value. After 24 hours, the water level continues to decrease, but the magnitude reduction slowed. This is mainly because the test site is a soft soil and deep water-rich sand layer with a large drainage distance, so the consolidation rate is slow. Pumping water in this type of formation will cause the groundwater level to change quickly and stabilize in a short time. However, due to the large drainage distance, settling speed is slower than dewatering speed.

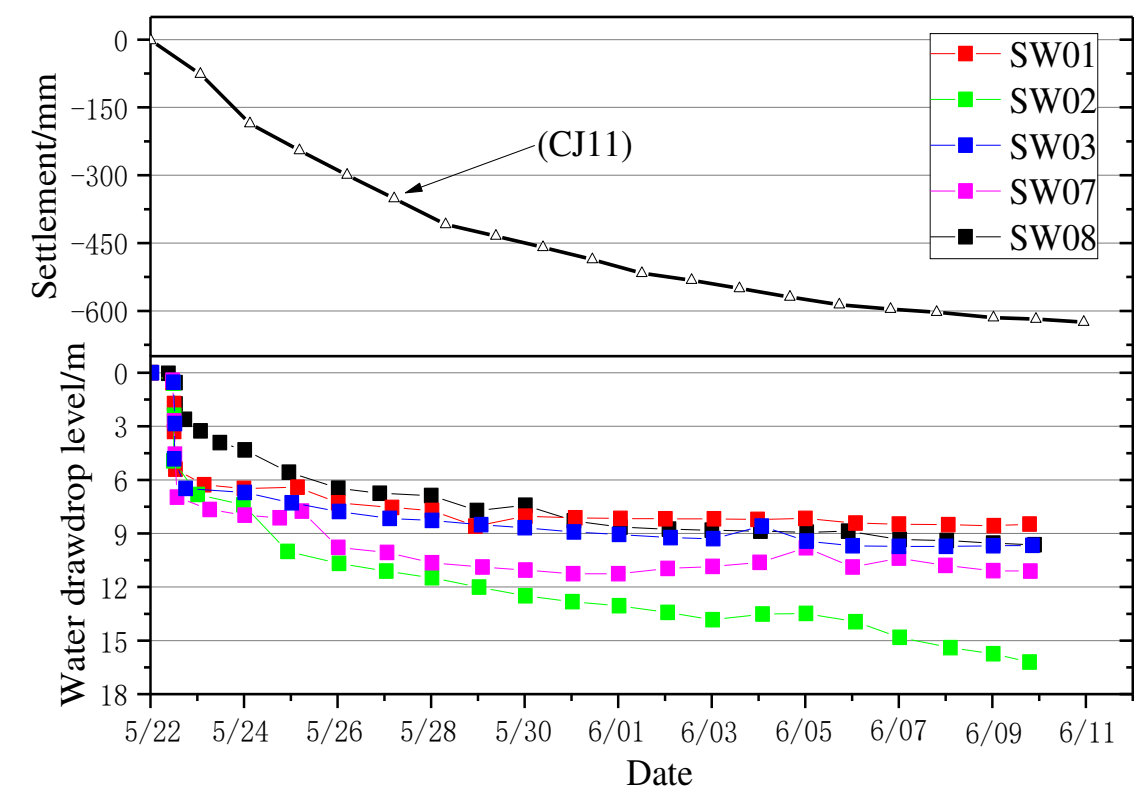

Fig.14. Variation curves of the groundwater levels at some typical monitoring points

\subsection{Pore water pressure}

To analyze the pore water pressure changes at different depths in the site during the pumping process, 4 sets of pore water pressure gauges were buried in the center of the three well spacing and the center of the site, respectively, KY01 (5m), KY02 (7m), KY03 (site Center), KY04 (14m). The pore pressure dissipation of each group of pore pressure gauges at the same depth varies with monitoring time as shown in Figure 13. It can be seen that the pore pressure dissipation curve is similar to the water drawdown level curve. The pore pressure dissipates faster in the early stage and slows down in the later stage. The pore water pressure dissipation value caused by pumping is about $90 \mathrm{kPa} \sim 120 \mathrm{kPa}$, which corresponds well to the groundwater drawdown level. Fig. 15(a) shows that the $15 \mathrm{~m}$ pore pressure at each monitoring point has basically approached zero, and the pore pressure at the center of the site has been less than zero, indicating that the groundwater level has fallen below this depth. Fig. 15(d) shows that the pore pressure at $30 \mathrm{~m}$ first decreases and then increases and then decreases, which is obviously different from other depths. This is mainly because the buried depth of pore water pressure gauge pair has reached the confined aquifer, and the groundwater is mainly pumped from the deeper pressure-reducing wells outside the site. In the previous section, the single-well porous pumping test has proved that the confined aquifer recovers quickly and there is a certain source of replenishment. Therefore, after the pore pressure drops to a certain value, it basically stabilizes, and even slightly 
increases. The rapid increase in pore pressure at 30 meters on June 3 was caused by the on-site decompression well stopping pumping. Fig. 15 also shows the maximum pore pressure dissipation value at each point. It can be seen that the KY02 pore pressure dissipation value at the center of the well pipe with a $7 \mathrm{~m}$ spacing is the largest, and its pore pressure dissipation value at $20 \mathrm{~m}$ reaches $160.9 \mathrm{kPa}$.
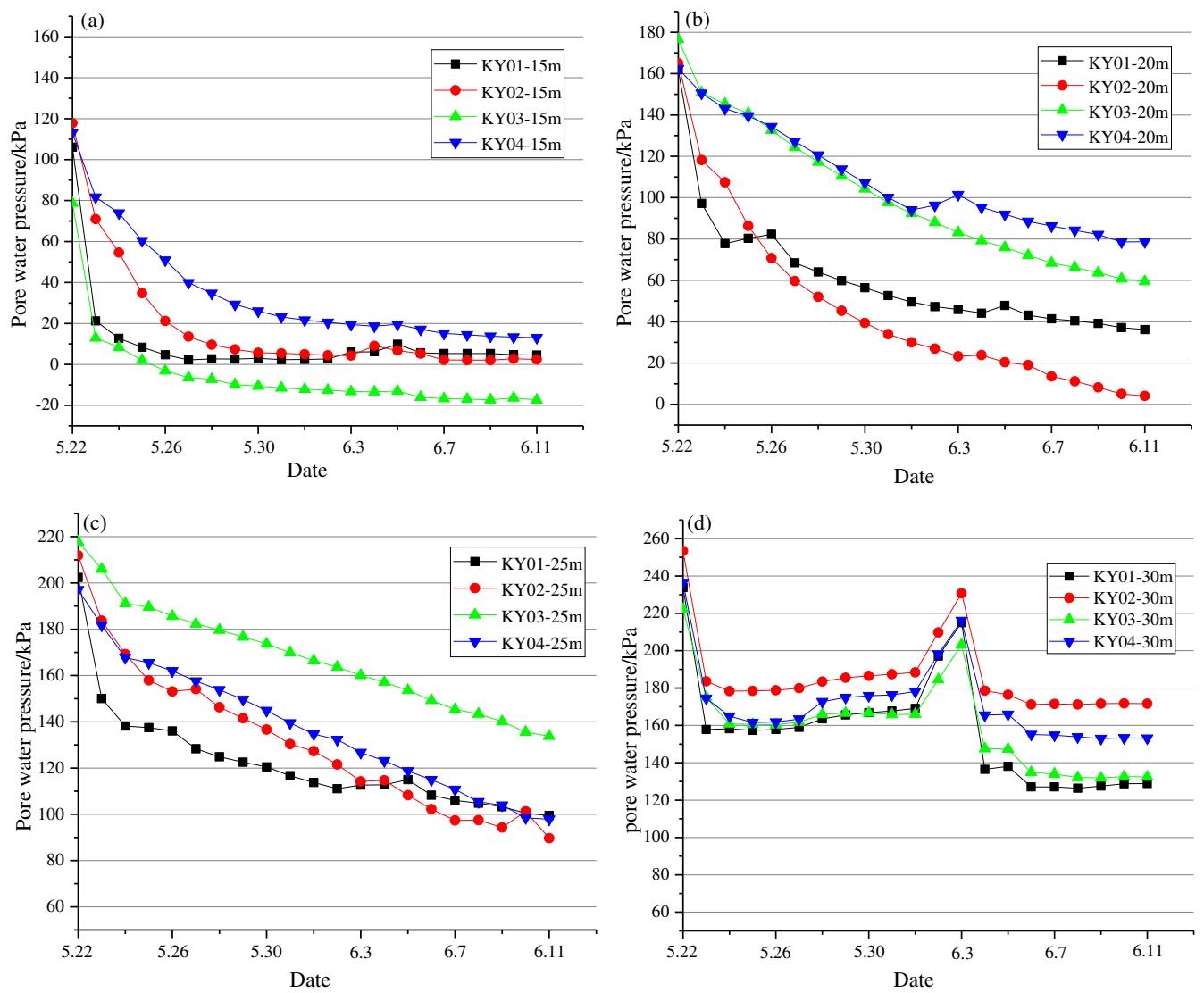

Fig.15. Curve of pore pressure dissipation (a) 15m; (b) 20m; (c) 25m; (d) 30m;

\subsection{CPTU test results}

Before and after the treatment, the CPTU in-situ test was performed at the center of the site. The cone tip resistance $q_{\mathrm{c}}$, side friction resistance $f_{\mathrm{s}}$, and pore pressure $u$ are measured as shown in Fig.16. The cone tip resistance $q_{\mathrm{c}}$ of the soil has been significantly increased after the treatment. Before treatment, $q_{\mathrm{c}}$ was between 0.2MPa 3MPa, with an average value of 1.09MPa. After treatment, it was increased to $0.5 \mathrm{MPa} \sim 7 \mathrm{MPa}$, with an average value of $1.83 \mathrm{MPa}$. Especially in the depth of the water drawdown level in the range of $5 \sim 15 \mathrm{~m}, q_{\mathrm{c}}$ has a large increase of about $110 \%$. And $f_{\mathrm{c}}$ has an increase of about $77.9 \%$. It indicates that the bearing capacity of the foundation has increased significantly. Moreover, the pore water pressure $u$ tested by CPTU has decreased, which is obvious. After treatment, it is 0 or close to 0 when the depth is above $15 \mathrm{~m}$. It is consistent with the field measurement results. It not only shows that the water in the upper part of the depth has been discharged by vacuum pumping, but also verifies the accuracy of the CPTU in-situ test results.

Based on the CPTU data and the empirical formula method, the undrained shear strength $S_{\mathrm{u}}$ and the compressive modulus $E_{\mathrm{s}}$ of the soil before and after the treatment can be estimated according to the measured cone tip resistance $q_{\mathrm{c}}$, the specific calculation method is shown in Eq.(11) Eq.(12).(Mayne and Kulhawy 1990; Xie et al. 2019). 


$$
S_{u}=\frac{q_{c}-\sigma_{v 0}}{N_{k}}
$$

$$
E_{\mathrm{S}}=a\left(q_{\mathrm{c}}-\sigma_{\mathrm{v} 0}\right)
$$

Where, $\sigma_{v 0}$ is the total overburden pressure $(\mathrm{kPa})$, and $N_{\mathrm{k}}$ is the empirical conic coefficient, with a

value range of 11-19, taken as 16. $a$ is the calculation coefficient. The range of $a$ is $3 \sim 8$ for most soft clay, taken as 3.5.

During the CPTU test, pore pressure dissipation tests at different depths were also carried out. According to the measured excess pore water pressure dissipation curve, Eq.(13) and Eq.(14) can be used to calculate the soil permeability coefficient $k_{\mathrm{h}}$ and consolidation coefficient $c_{\mathrm{h}}$, and other important soil engineering property parameters (Chai et al. 2004).

$$
c_{h}=\frac{T^{*} \cdot r^{2} \cdot \sqrt{I_{r}}}{t_{50}}
$$

$$
k_{h}=\left(251 t_{50}\right)^{-1.25}
$$

Where, $r$ is the probe radius, taking the value $17.85 \mathrm{~mm}$; $I_{\mathrm{r}}$ is the stiffness index, $I_{\mathrm{r}}=G / S_{\mathrm{u}}, G$ is the shear modulus $(\mathrm{kPa}) ; t_{50}$ is the time when the over pore pressure dissipates to $50 \%$, it can be checked on the drawn normalized over pore pressure curve(s). $T^{*}$ is the time factor corresponding to $t_{50}$, taken as 0.245 .
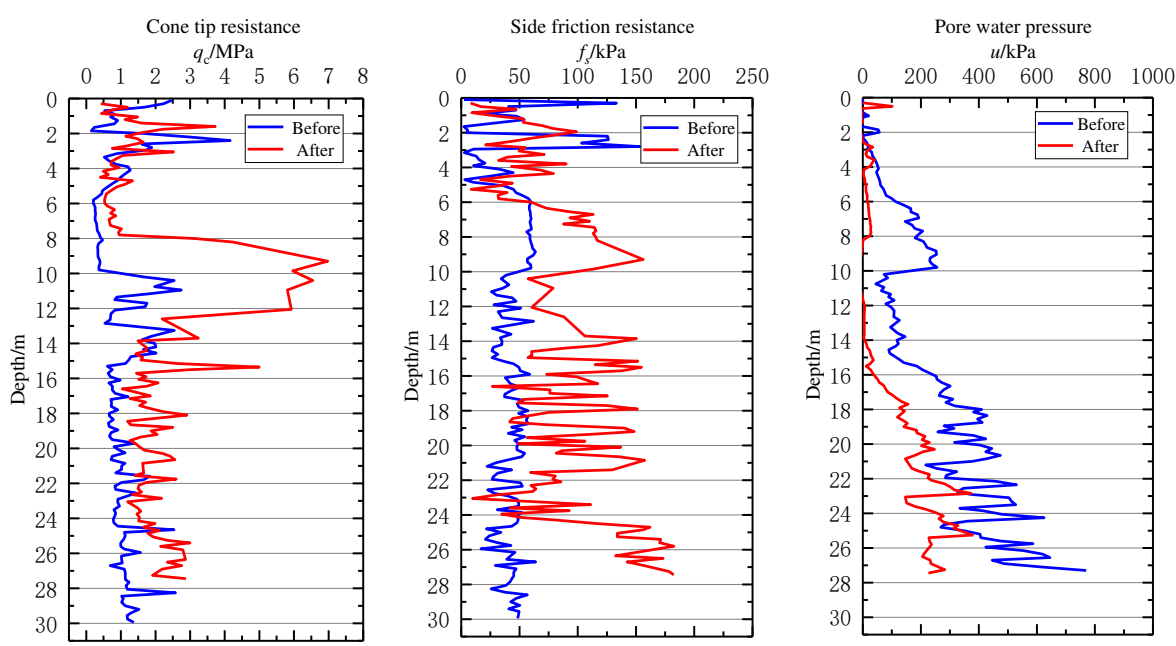

Fig.16. CPTU test curve

According to the CPTU test results, the main engineering parameters of the soil before and after the treatment are shown in Table 5. It can be seen that the undrained shear strength of each soil layer increased by $13.6 \%-193.9 \%$ after the treatment, especially the strength of the soft soil layer (3) and (4) increased significantly; the compressive modulus increased by about $357.4 \%$ 515.1\%, indicating that the compressibility of soil is small, the bearing performance of the foundation is enhanced; the 
consolidation coefficient and the permeability coefficient is reduced. The vacuum tube-well has a significant effect of dewatering and consolidation.

Table 5 Changes of main engineering parameters of soil before and after treatment

\begin{tabular}{|c|c|c|c|c|c|c|c|c|c|c|}
\hline \multirow[t]{2}{*}{$\operatorname{depth}(m)$} & \multirow{2}{*}{$\begin{array}{c}\text { layer } \\
\text { number }\end{array}$} & \multirow{2}{*}{$\begin{array}{l}\text { type of Soil } \\
\text { layer }\end{array}$} & \multicolumn{2}{|c|}{$\begin{array}{l}\text { undrained shear } \\
\text { strength } S_{\mathrm{u}}(\mathrm{kPa})\end{array}$} & \multicolumn{2}{|c|}{$\begin{array}{c}\text { compression } \\
\text { modulus } E_{s}(\mathrm{MPa})\end{array}$} & \multicolumn{2}{|c|}{$\begin{array}{c}\text { consolidation coefficient } \\
\qquad c_{h}\left(10^{-3} \mathrm{~cm}^{2} / \mathrm{s}\right)\end{array}$} & \multicolumn{2}{|c|}{$\begin{array}{l}\text { ermeability coefficient } \\
\qquad k_{h}\left(10^{-5} \mathrm{~cm} / \mathrm{s}\right)\end{array}$} \\
\hline & & & before & after & before & after & before & after & before & after \\
\hline $0 \sim 2.3$ & (1) & new fill & - & & - & & & & & \\
\hline $2.3 \sim 4$ & (2) & silty clay & 103.4 & 117.52 & 4.77 & 14.49 & & & & \\
\hline $4 \sim 10$ & (3) & $\begin{array}{l}\text { sludge-Silty } \\
\text { clay }\end{array}$ & 24.27 & 150.07 & 3.2 & 19.81 & 2.11 & 0.49 & 0.84 & 0.019 \\
\hline $10 \sim 15$ & (4) & silt sand-clay & 101.03 & 261.39 & 13.33 & 34.50 & & & & \\
\hline $15 \sim 30$ & (5) & $\begin{array}{l}\text { sludge-Silty } \\
\text { clay }\end{array}$ & 51.86 & 155.34 & 6.84 & 20.51 & & & & \\
\hline
\end{tabular}

Note: The soil layer classification in this table is based on CPTU test data, which is different from Table 1.

\subsection{Settlement prediction}

Prediction of final settlement is an important part of soft soil ground treatment. There are many methods for the calculation and prediction of ground settlement. According to its application principles, it can be basically divided into two categories. One is a purely theoretical calculation method based on the principle of soil consolidation and compression, such as layerwise summation method and numerical calculation method. And the other is a settlement prediction method based on measured settlement data, including the Asaoka method (Asaoka 1978), the hyperbola method (Sridharan et al. 1981), and the logarithmic curve method (Zeng et al. 1981).

In this study, an empirical hyperbolic method introduced by Technical Specification for Vacuum Preloading Technique to Improve Soft Soils (Ministry of Transport of China 2009) was used to predict settlement. Assume that the total settlement of soils $S_{\mathrm{t}}$ consisted of two parts: Settlement of initial reference point $\left(S_{0}\right)$ and the subsequent one, which can be fitted by the formula of the hyperbola. $S_{\mathrm{t}}$ can be calculated by Eq. (15).

$$
S_{\mathrm{t}}=S_{0}+\frac{t-t_{0}}{\alpha+\beta\left(t-t_{0}\right)}
$$

When $t \rightarrow \infty$, the final settlement $S_{\infty}$ can be calculated by Eq. (16).

$$
S_{\infty}=S_{0}+\frac{1}{\beta}
$$

Where, $S_{\infty}$ is the settlement by dewatering and consolidation(m); $S_{0}$ and $t_{0}$ are initial reference point settlement and observation time(d). $S_{t}$ is the settlement at time t. $\alpha$ and $\beta$ are calculation parameters, which are the intercept and slope of the fitted curve, respectively. 

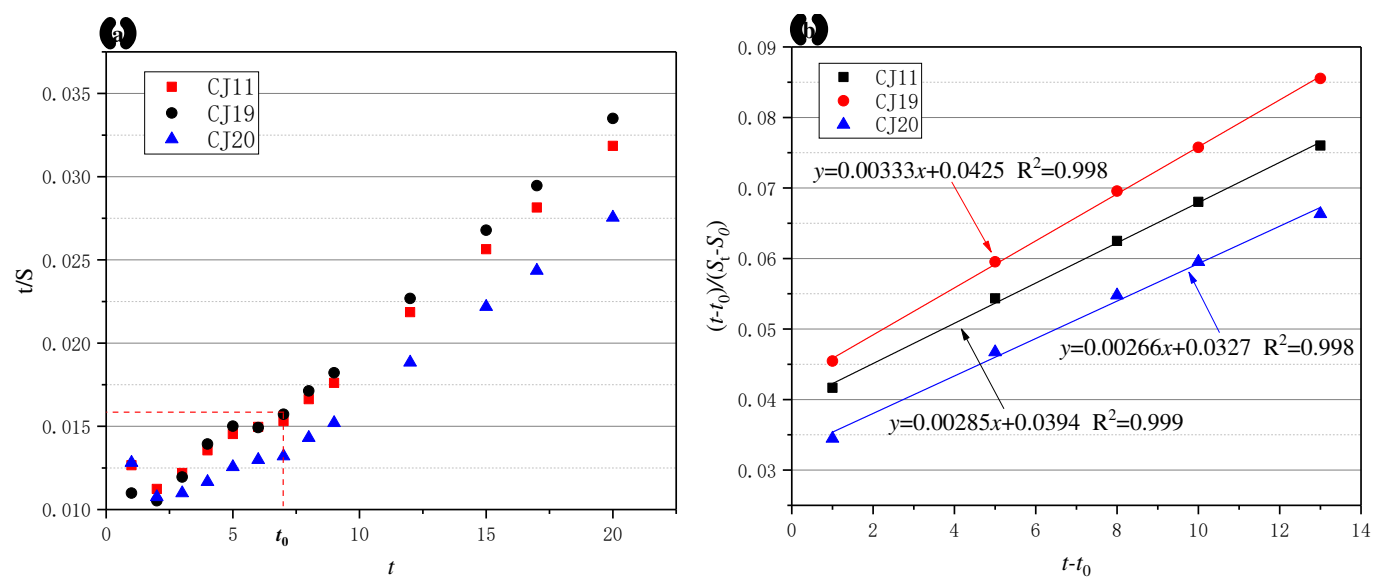

Fig.17 Settlement prediction curve(a) hyperbola of settlement and time; (b) fitting curve

Select the data of three representative settlement monitoring points for prediction, they are CJ11 (center), CJ19 (left) and CJ20 (right) respectively. According to the hyperbola of settlement and time (Fig.17(a)), the settlement at $t_{0}=7$ can be used as the initial reference point $S_{0}$. Perform linear fitting on the settlement monitoring data after $t_{0}$, and get the fitting curve as shown in Fig.17(b). According to the fitting curve, the calculation parameters $\alpha$ and $\beta$ are obtained and the final settlement of each monitoring point is calculated as shown in Table 6. Comparing the settlement value measured in 20 days $\left(S_{20}\right)$, the degree of consolidation(U) after the end of the pumping can be calculated. It can be seen that the degree of consolidation of the three measuring points of $\mathrm{CJ} 11$, CJ19, and CJ20 are 76.5\%, $79.1 \%$ and $80.1 \%$, respectively. After 60 days of the test, the degree of consolidation of each monitoring point is greater than $94 \%$. Many scholars have introduced the cases of soft soil treatment by vacuum preloading. The treatment time for most cases to reach the similar consolidation degree is more than 100 days, and some cases even more than 300 days (Ding et al. 2019; Wu et al. 2020; Indraratna et al. 2011). Therefore, the consolidation efficiency of vacuum tube-well dewatering technology has obvious advantages.

Table.6 Settlement prediction results of each monitoring point

\begin{tabular}{ccccccccc}
\hline monitoring point & $\boldsymbol{S}_{\mathbf{0}}(\mathbf{m m})$ & $\boldsymbol{\alpha}$ & $\boldsymbol{\beta}$ & $\boldsymbol{S}_{\infty}(\mathbf{m m})$ & $\boldsymbol{S}_{\mathbf{2 0}}(\mathbf{m m})$ & $\boldsymbol{U}_{\mathbf{2 0}}(\boldsymbol{\%})$ & $\boldsymbol{S}_{\mathbf{6 0}}(\mathbf{m m})$ & $\boldsymbol{U}_{\mathbf{6 0}}(\boldsymbol{\%})$ \\
\hline CJ11 & 457 & 0.00285 & 0.00394 & 808 & 628 & 76.5 & 766 & 94.8 \\
CJ19 & 455 & 0.00333 & 0.00425 & 755 & 597 & 79.1 & 714 & 94.6 \\
CJ20 & 530 & 0.00266 & 0.00289 & 906 & 726 & 80.1 & 853 & 94.2 \\
\hline
\end{tabular}

Note: $S_{20}$ and $S_{60}$ are the monitored settlement for 20 days and 60 days, respectively. $U_{20}$ and $U_{60}$ are the corresponding degree of consolidation.

\section{Conclusion}

Preloading the deep soft soil in the Yangtze River floodplain with vacuum tube-well and conducting some field monitoring tests. The following conclusions can be drawn from this paper.

Deep soft soil of the Yangtze River floodplain area in Nanjing has a special interlayer structure. The clay layer is sandwiched with a thin layer of silt sand, and obvious horizontal thin bedding is formed, which is similar to the horizontal drainage plate in the soil. This special structure provides favorable conditions for the application of vacuum tube-well. However, in some clay layers with low permeability coefficients, the application of this method may be limited.

Based on the single-well multi-hole pumping test, the hydraulic connection between the site aquifers was found. The permeability coefficient, outflow and influence radius of the confined aquifer and 
phreatic aquifer of the site were calculated by using the experimental observation data. Furthermore, the layout of vacuum tube-wells and depressurization wells in a test site with $84 \mathrm{~m}$ length and 84 width was designed based on the above parameters.

Field test of vacuum tube-well dewatering technology was carried out on the test site . The results showed that the surface subsidence and water drawdown level do not increase with the decrease of the well pipe spacing due to the mutual interference of vacuum negative pressure. There is an optimal spacing. In this test site, the $7 \mathrm{~m}$ spacing has the best treatment effect. The settlement of the entire site decreases radially from the center to the surrounding with $7 \mathrm{~m}$ spacing wells. The settlement on the right side of the test site (vacuum tube-well) is higher than that on the left side (no-vacuum tube-well), indicating that the vacuum negative pressure can increase the pumping rate and the consolidation effect.

The pore water pressure tested by CPTU is basically consistent with the field measured value. And after treatment, the cone tip resistance $q_{\mathrm{c}}$ and side friction resistance $f_{\mathrm{s}}$ of the soil has been significantly increased. Especially in the depth range where the groundwater drawdown levels, $q_{\mathrm{c}}$ and $f_{\mathrm{s}}$ increased by about $110 \%$ and $77.49 \%$ respectively. It is indicated that the foundation bearing capacity was significantly improved. Based on the CPTU pore pressure dissipation test, it was found that the undrained shear strength $S_{\mathrm{u}}$ of the treated soil increased by $13.6 \% \sim 193.9 \%$, the compressive modulus $E_{\mathrm{s}}$ increased by $357.4 \% \sim 515.1 \%$, and the engineering properties of the soil were significantly improved.

Combined with the settlement monitoring data, the hyperbolic method was used to predict the final settlement. The time required for vacuum tube-well dewatering technology to reach $94 \%$ degree of consolidation is about 60 days, which is faster than the vacuum preloading method. Therefore, consolidation efficiency of vacuum tube-well dewatering technology has obvious advantages.

\section{Declarations}

Funding This study was financially supported by the Science and Technology Guidance Project of Jiangu Housing and Urban-Rural Development Department in China (2020ZD001203). Many Thanks to Professor Guangyin Du for his suggestions to the analysis and discussion of this paper. Great thanks also go to the editorial board and the reviewers of this paper.

Conflicts of interest There are no conflicts of interest.

Availability of data and material All data generated or analyzed during this study are included in this published article.

Code availability Not applicable.

\section{Authors' contributions}

Songyu Liu, Dingwen Zhang contributed to the conception of the study;

Biao Zeng, Yu Zhen performed the field test and on-site monitoring;

Dingwen Zhang, Tao Meng contributed significantly to analysis and manuscript preparation;

Biao Zeng performed the data analyses and wrote the manuscript;

Gong Zejia helped with the calculation and revision work. 


\section{References}

Iqbal, J, Thomasson, J A, Jenkins, J N et al (2005). Spatial variability analysis of soil physical properties of alluvial soils. Soil Sci Soc Am J 69(4):1338-1350

Cai, G, Zou, H, Liu, S, \& Puppala, A J (2017). Random field characterization of CPTU soil behavior type index of Jiangsu quaternary soil deposits. B Eng Geol Environ 76(1): 353-369

Xia, J, Huang, G L, \& Yan, S B (2006). Behavior and engineering implications of recent floodplain soft soil along lower reaches of the Yangtze River in Western Nanjing, China. Eng Geol 87(1-2): 48-59

Shi X S, Herle I (2017). Numerical simulation of lumpy soils using a hypoplastic model. Acta Geotech, 12(2):1-15

Shi, X S, Herle, I M W D, \& Muir Wood, D (2018). A consolidation model for lumpy composite soils in open-pit mining. Géotechnique 68(3):189-204

Ding, J, Wan, X, Zhang, C et al (2019). Case study: ground improvement of Yangtze river floodplain soils with combined vacuum and surcharge preloading method. Int J Geomech 19(12): 05019008.1-05019008.13

Mesri G, Khan A Q (2012). Ground improvement using vacuum loading together with vertical drains. J Geotech Geoenviron 138(6): 680-689

Indraratna, B. (2010). Recent advances in the application of vertical drains and vacuum preloading in soft soil stabilisation. Australian Geomechanics Journal, 45(2)

Chai, J C, Carter, J P, Hayashi, S (2005). Ground deformation induced by vacuum consolidation. J Geotech Geoenviron 131(12):1552-1561

Wang, J, Ni, J, Cai, Y et al (2017). Combination of vacuum preloading and lime treatment for improvement of dredged fill. Eng Geol 227:149-158

Lei, H, Lu, H, Liu, J et al (2017). Experimental study of the clogging of dredger fills under vacuum preloading. Int J Geomech 17(12): 04017117

Wang, J, Cai, Y, Ma, J et al (2016). Improved vacuum preloading method for consolidation of dredged clay-slurry fill. J Geotech Geoenviron 142(11): 06016012

Sargent, D. W. , Beckie, R. D., Smith, G. .(1998). Design and performance of deep well dewatering: a case study. Can Geotech J 35(1): 81-95.

Cashman P M, Preene M (2020). Groundwater lowering in construction: a practical guide to dewatering[M]. CRC Press, Florida

Zhang D D (2017). Study on dewatering and decompression technology of deep soft soil foundation pit. Doctor Thesis of Shanghai Jiao Tong University.

Han J (2015). Principles and practice of ground improvement. John Wiley \& Sons, New Jersey

Shen S L, Xu Y S (2011). Numerical evaluation of land subsidence induced by groundwater pumping in Shanghai. Can Geotech J 48(9): 1378-1392

Indraratna, B, Sathananthan, I, Rujikiatkamjorn, C et al (2005). Analytical and numerical modeling of soft soil stabilized by prefabricated vertical drains incorporating vacuum preloading. Int J Geomech 5(2): 114-124

Wu Y X, Shen S L, Yuan D J (2016). Characteristics of dewatering induced drawdown curve under blocking effect of retaining wall in aquifer. J Hydrol 539: 554-566

Pan X M (2009). Application research of vacuum tube-well compound dewatering technology. Master Thesis of China University of Geosciences (Beijing)

Ahmad I, Tayyab M, Zaman M et al (2019). Finite-difference numerical simulation of dewatering system in a large deep foundation pit at Taunsa Barrage, Pakistan. Sustainability-Basel, 11(3): 694 
Luo Z, Zhang Y, Wu Y (2008). Finite element numerical simulation of three-dimensional seepage control for deep foundation pit dewatering. J Hydrodyn, 2008, 20(5): 596-602

Rujikiatkamjorn C, Indraratna B (2007). Analytical solutions and design curves for vacuum-assisted consolidation with both vertical and horizontal drainage. Can Geotech J 44(2): 188-200

Huang F (2014). Mechanism research of vacuum tube dewatering method. Doctor Thesis of China University of Geosciences (Beijing)

Indraratna B, Redana I W (2000). Numerical modeling of vertical drains with smear and well resistance installed in soft clay. Can Geotech J 37(1): 132-145

Jia X X, Nie Q K, Wang Y, H, et al (2014). Analysis and numerical simulation of vacuum well point dewatering test. Rock and Soil Mechanics,35(2):607-618

Liu H L, Zhao M H (2016). Review of ground improvement technical and its application in China. China Civil Engineering Journal, 049(001):96-115

Liu J, Luo Y, Zhang G X et al (2009). Experimental research on saturated mucky foundation treatment with well-point dewatering combined with dynamic compaction method . Chinese Journal of Rock Mechanics and Engineering, 28(11): 2222-2227

China Geological Survey Bureau (2013). The hydrogeology manual of China: second edition. Geological Publishing House, Beijing

Ministry of Housing and Urban-Rural Development of China (2016). Technical code for groundwater control in building and municipal engineering. China Architecture Publishing, Beijing

Cai G J, Liu S Y, Tong L Y et al (2009). Comparative study of modern digital multifunctional CPTU and china's CPT tests. Chinese Journal of Rock Mechanics and Engineering, 28 (05): 914-928

Xie WQ, Cai G J, Wang R et al (2019). Prediction of the undrained shear strength of clay from CPTu data using artificial neural network. China Civil Engineering Journal, 2019(S2): 35-41

Mayne P W, Kulhawy F H (1990). Direct and indirect determinations of in situ k sub 0 in clays. Transport Res Rec (1278)

Chai J C, Carter J P, Miura N, et al (2004). Coefficient of consolidation from piezocone dissipation test. Proc. of Int. Symposium on Lowland Technology, ISLT: 1-6

Asaoka, A. (1978). Observational procedure of settlement prediction. Soils Found. 18 (4): 87-101

Sridharan, A., Rao, A. S. (1981). Rectangular hyperbola fitting method for one dimensional consolidation. International Journal of Rock Mechanics \& Mining Science \& Geomechanics Abstracts, 4(4):161-168

Zeng, G.X., Wang, T.R., Gu, Y.Z., (1981). Some aspects of sand-drained ground. In: Proceedings of the 10th International Conference on Soil Mechanics and Foundation Engineering. Stockholm, vol. 1: 835-838

Ministry of Transport of China (2009). Technical specification for vacuum preloading technique to improve soft soils. China Communications Press, Beijing

Wu J , Xuan Y, Deng Y, et al (2021). Combined vacuum and surcharge preloading method to improve lianyungang soft marine clay for embankment widening project: A case. Geotext Geomembranes 49: 452-465

Indraratna, B., Rujikiatkamjorn, C., Ameratunga, J., Boyle, P., (2011). Performance and prediction of vacuum combined surcharge consolidation at Port of Brisbane. J. Geotech. Geoenviron. Eng. 137 (11), 1009 - 1018. 